\title{
Activity Level-Dependent Synapse-Specific AMPA Receptor Trafficking Regulates Transmission Kinetics
}

\author{
J. Julius Zhu \\ Departments of Pharmacology and Neuroscience, University of Virginia School of Medicine, Charlottesville, Virginia 22908
}

Central glutamatergic synapses may express AMPA-sensitive glutamate receptors (AMPA-Rs) with distinct gating properties and exhibit different transmission dynamics, which are important for computing various synaptic inputs received at different populations of synapses. However, how glutamatergic synapses acquire AMPA-Rs with distinct kinetics to influence synaptic integration remains poorly understood. Here I report synapse-specific trafficking of distinct AMPA-Rs in rat cortical layer 4 stellate and layer 5 pyramidal neurons. The analysis indicates that in single layer 4 stellate neurons thalamocortical synapses generate faster synaptic responses than intracortical synapses. Moreover, GluR1-containing AMPA-Rs traffic selectively into intracortical synapses, and this process requires sensory experience-dependent activity and slows down transmission kinetics. GluR4-containing AMPA-Rs traffic more heavily into thalamocortical synapses than intracortical synapses, and this process requires spontaneous synaptic activity and speeds up transmission kinetics. GluR2-containing AMPA-Rs traffic equally into both thalamocortical and intracortical synapses, and this process requires no synaptic activity and resets transmission kinetics. Notably, synaptic trafficking of distinct AMPA-Rs differentially regulates synaptic integration. Thus, synapse-specific AMPA-R trafficking coarsely sets and synaptic activity finely tunes transmission kinetics and integration properties at different synapses in central neurons.

\section{Introduction}

Different populations of glutamatergic synapses in single neurons may express AMPA-sensitive glutamate receptors (AMPARs) with distinct gating properties and exhibit different transmission dynamics, which are important for computing various synaptic inputs received at different synapses (Rubio and Wenthold, 1997; Tóth and McBain, 1998; Jonas, 2000; Gardner et al., 2001; Kielland et al., 2009). In addition, the same populations of glutamatergic synapses in the same neuron may also display a considerable variance in transmission efficacy and kinetics, reflecting a high capacity for synaptic plasticity (Stern et al., 1992; Markram et al., 1997; Tóth and McBain, 1998; Gil et al., 1999; Gardner et al., 2001; Petersen et al., 2003; Kalisman et al., 2005; Cheetham et al., 2007). These findings raise important questions of how different synapses in single neurons acquire distinct AMPA-Rs and response dynamics and whether the process affects synaptic integration.

Synaptic trafficking of AMPA-Rs has been examined at various synapses ( $\mathrm{Gu}$ and Stornetta, 2007; Isaac et al., 2007; Kauer and Malenka, 2007; Shepherd and Huganir, 2007; Kerchner and Nicoll, 2008; Kessels and Malinow, 2009). The cytoplasmic C termini of the constituent AMPA-R subunits, which can be either long or short, define the synaptic trafficking characteristics.

Received Sept. 25, 2008; revised Feb. 26, 2008; accepted April 9, 2009.

This study was supported by an Alfred P. Sloan fellowship and the National Institutes of Health. I thank Drs. Barry Connors, John Isaac, and Ruth Stornetta for helpful discussions and members of the Zhu laboratory for comments and help with some experiments.

Correspondence should be addressed to J. Julius Zhu, Department of Pharmacology, University of Virginia School of Medicine, 1300 Jefferson Park Avenue, Charlottesville, VA 22908. E-mail: jzhu@virginia.edu.

DOI:10.1523/JNEUROSCI.4630-08.2009

Copyright $\odot 2009$ Society for Neuroscience $\quad$ 0270-6474/09/296320-16\$15.00/0
AMPA-Rs with long cytoplasmic termini (i.e., GluR1-, GluR2L-, and GluR4-containing AMPA-Rs) are driven into synapses during synaptic enhancement. Whereas strong or sensory experience-dependent synaptic activity is required for synaptic delivery of GluR1-containing AMPA-Rs, spontaneous synaptic activity is sufficient to drive GluR2L- and GluR4-containing AMPA-Rs into synapses. AMPA-Rs with only short cytoplasmic termini (i.e., GluR2/3) cycle between nonsynaptic and synaptic sites in an activity-independent manner and exchange or replace synaptic receptors without changing the synaptic efficacy; their number at synapses can be reduced after activity-induced synaptic depression. However, whether all or only selective types of AMPA-Rs traffic into certain populations of glutamatergic synapses remains poorly understood. Because different AMPA-Rs have distinct gating kinetics (i.e., from slow to fast: GluR1 $\rightarrow$ GluR2 $\rightarrow$ GluR4) (Mosbacher et al., 1994; Geiger et al., 1995; Jonas, 2000), an obvious unanswered question is whether and how synaptic AMPA-R trafficking and/or synaptic activity regulates transmission kinetics and information integration at different synapses in single neurons. To address this question, I developed two new experimental approaches that combine an in vivo recombinant DNA delivery technique (McCormack et al., 2006) with either an in vitro thalamocortical brain slice preparation (Agmon and Connors, 1991) or an in vitro intact cortical layer 1 input-layer 5 cell slice preparation (Zhu, 2000). These preparations allow investigation of the regulated AMPA-R trafficking at different populations of synapses in single layer 4 stellate neurons and single large tufted layer 5 pyramidal neurons of the barrel cortex. The results suggest that distinct AMPA-Rs differentially traffic into different populations of synapses in single cortical neurons, which has a 


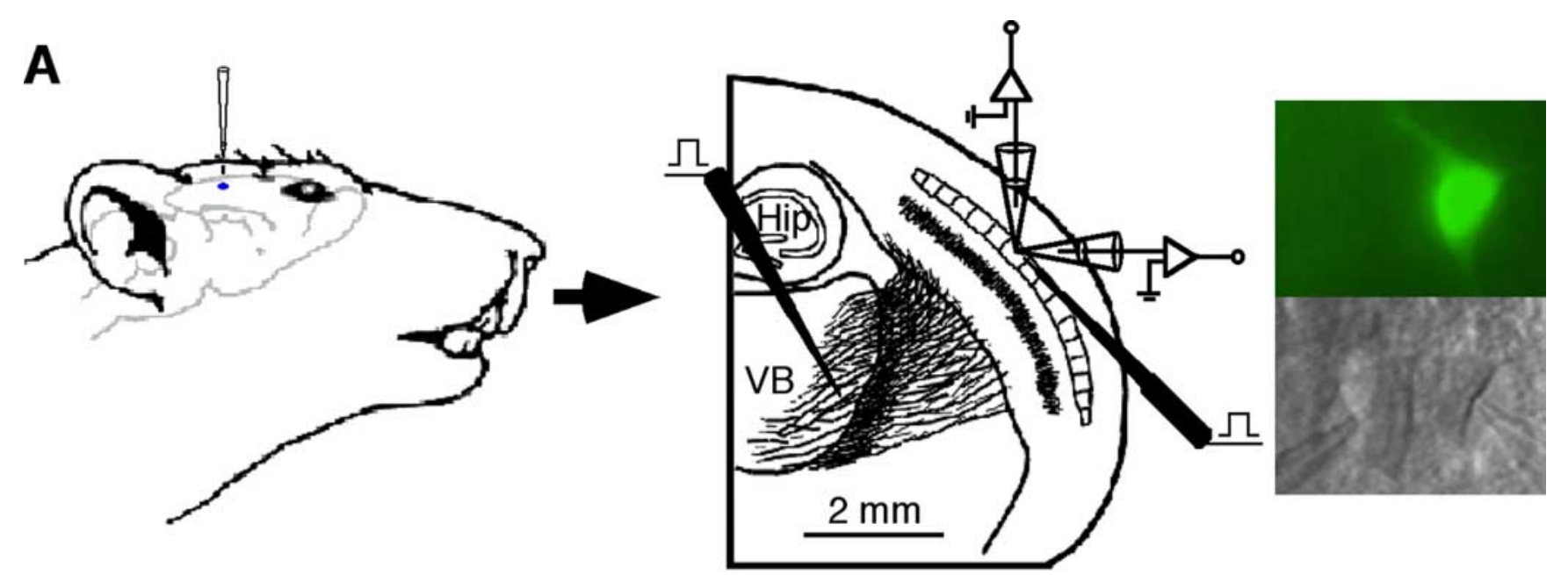

B

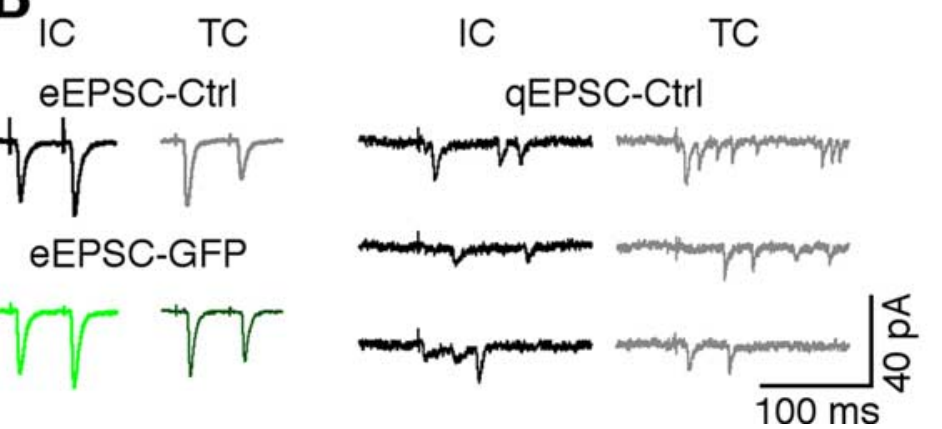

C

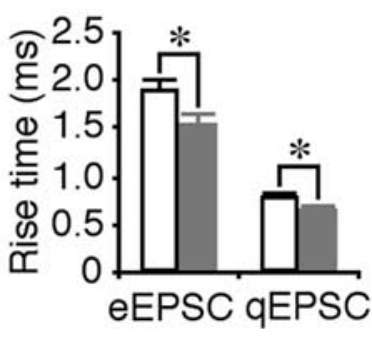

$\square \mathrm{IC} \square \mathrm{TC}$

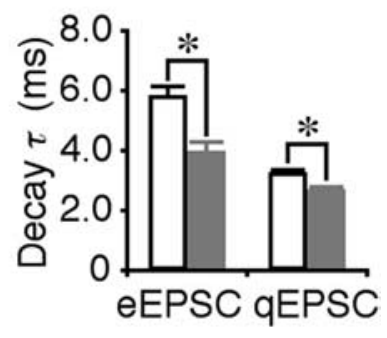

Figure 1. Intracortical and thalamocortical synapses possess different transmission kinetics. $\boldsymbol{A}$, Left and middle, Schematic drawing of the in vivo injection of viral constructs, in vitro stimulating and recording electrode locations in the thalamocortical slice preparation. Hip, Hippocampus; VB, ventral basal nucleus. Right, Simultaneous recordings, made under transmitted light illumination (bottom), from pairs of recombinant protein-expressing neurons, identified by GFP fluorescence (top), and nearby nonexpressing control neurons in layer 4 . $\boldsymbol{B}$, Left traces, evoked EPSCs (eEPSCS) from intracortical (IC) and thalamocortical (TC) synapses from a pair of layer 4 neurons. Note the paired-pulse facilitation of intracortical responses and depression of thalamocortical responses of both control nonexpressing and expressing neurons. Right traces, Asynchronous quantal EPSCs (qEPSCs) from intracortical and thalamocortical synapses in a layer 4 neuron. $C$, Left, Rise time of eEPSPs (IC, $1.87 \pm 0.12 \mathrm{~ms} ; \mathrm{TC}, 1.52 \pm 0.12 \mathrm{~ms} ; n=18 ; p<0.05)$ and qEPSCs (IC, $0.78 \pm 0.03 \mathrm{~ms} ; \mathrm{TC}, 0.63 \pm 0.03 \mathrm{~ms} ; n=20 ; p<0.005)$ from intracortical and thalamocortical synapses. Right, Decay time constant of eEPSPs $(\tau ; \mathrm{IC}, 5.70 \pm 0.47 \mathrm{~ms} ; \mathrm{TC}, 3.91 \pm 0.32 \mathrm{~ms} ; n=18 ; p<0.005)$ and $q \mathrm{EPSCs}(\tau ; \mathrm{IC}, 3.16 \pm 0.14 \mathrm{~ms} ; \mathrm{TC}, 2.49 \pm 0.11 \mathrm{~ms} ; n=20 ; p<0.0005)$ from intracortical and thalamocortical synapses. ${ }^{*} p<0.05$ (Wilcoxon's test).

profound impact on information integration at different populations as well as individual synapses.

\section{Materials and Methods}

Constructs and expression of recombinant proteins. Constructs were made as described previously (Zhu et al., 2000; Kolleker et al., 2003) and expressed in postnatal day 14 and older (postnatal day 27) rat barrel cortex. Expression was achieved using Sindbis virus as in previous reports (Qin et al., 2005; McCormack et al., 2006; Hu et al., 2008). In brief, rats were initially anesthetized by an intraperitoneal injection of ketamine and xylaxine (10 and $2 \mathrm{mg} / \mathrm{kg}$, respectively). Animals were then placed in a stereotaxic frame, and a hole $\sim 1 \times 1 \mathrm{~mm}$ was opened above the center of the right barrel cortex. A glass pipette was used to penetrate into layer 4 or layer 5 according to stereotaxic coordinates, and $\sim 50 \mathrm{nl}$ of buffer solution containing one or mixtures of two viruses was delivered by pressure injection. After injection, animals were allowed to recover from the anesthesia and then returned to their dams. To manipulate experiencedependent or -independent synaptic activity during expression of recombinant proteins, either all large whiskers on the contralateral face were trimmed after the delivery of viral constructs or $\sim 100 \mathrm{nl}$ of TTX $(100 \mu \mathrm{M})$ was coinjected into several places at and close to the virus injection site using a glass pipette. Action potential-independent spontaneous synaptic activity (i.e., miniature EPSCs), which has little impact on the membrane potential in vivo, does not affect synaptic AMPA-R trafficking (Zhu et al., 2000; McCormack et al., 2006). Thus, this form of activity was not included in analysis and discussion in this study. All electrophysiology and biochemistry experiments were performed within $20 \mathrm{~h}$ after expression (typically $15 \pm 3 \mathrm{~h}$ after expression unless stated otherwise) to prevent excessive overexpression of recombinant proteins. No compensatory/secondary effect was expected for this expression period (Zhu and Malinow, 2002; Qin et al., 2005), which was confirmed by the same NMDA responses and basic membrane properties in glutamate receptor (GluR)-green fluorescent protein (GFP) expressing and nonexpressing neurons (see Figs. 2-5) (supplemental Fig. S1, available at www.jneurosci.org as supplemental material). Moreover, for this expression period, the GFP-tagged cytoplasmic termini of GluR1 (GluR1ctGFP), GluR2 (GluR2ct-GFP), GluR2L (GluR2Lct-GFP), and GluR4 (GluR4ct-GFP) retain their specificity in selectively blocking synaptic trafficking of endogenous heteromeric GluR1-, GluR2-, GluR2L-, and GluR4-containing AMPA-Rs, respectively (Zhu et al., 2000; Kolleker et al., 2003; Qin et al., 2005; Kielland et al., 2009). For electrophysiology measurements, 350- $\mu \mathrm{m}$-thick thalamocortical slices (Agmon and Connors, 1991) or intact cortical layer 1 input-layer 5 cell slices (Zhu, 2000) were prepared from the infected brains. Slices were incubated at $37.0 \pm$ $0.5^{\circ} \mathrm{C}$ in oxygenated physiological solution for $\sim 1 \mathrm{~h}$ before recordings. For biochemistry measurements, cortical layer 4 areas with high infec- 


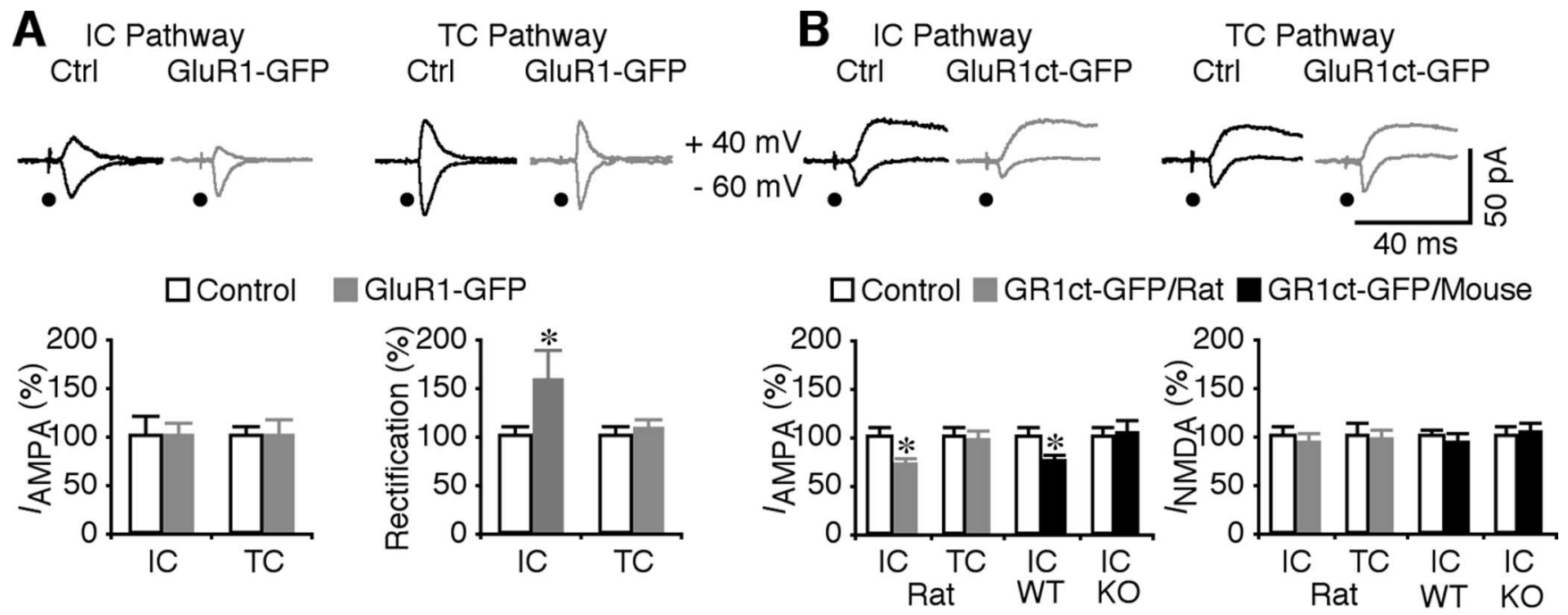

\section{With Whiskers Trimmed}
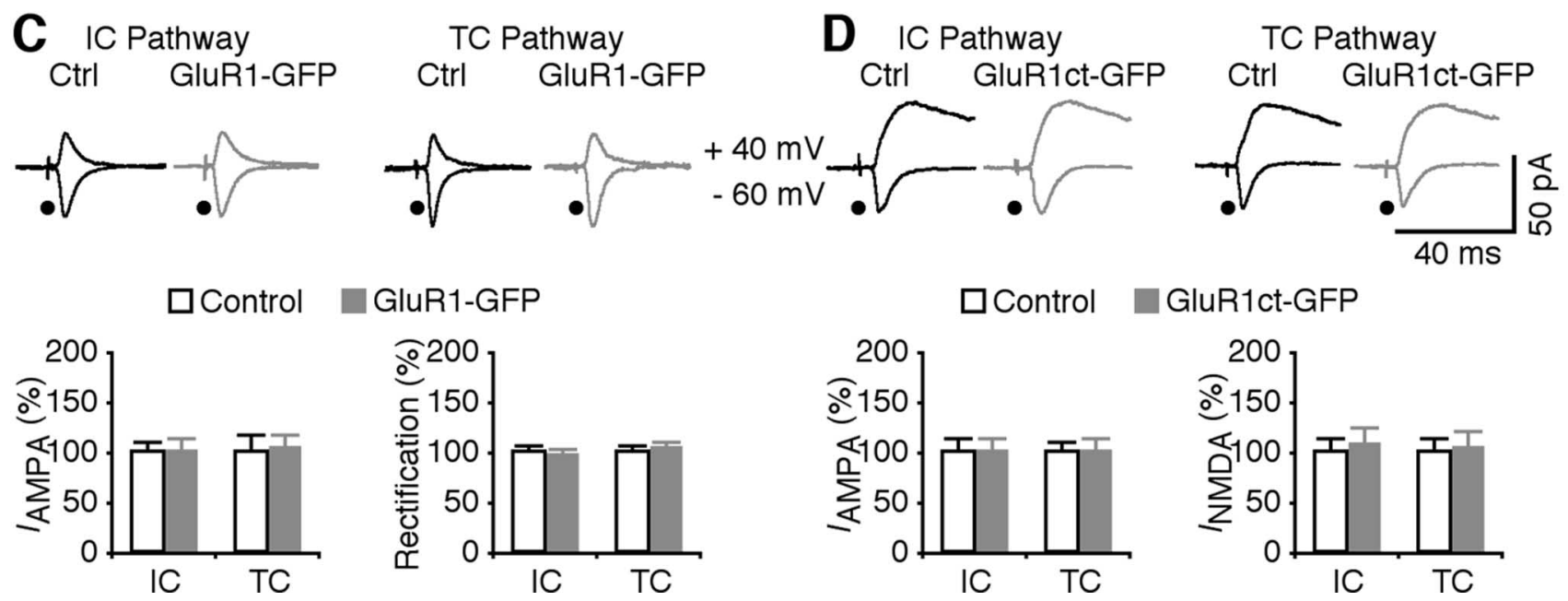

GluR1-GFP

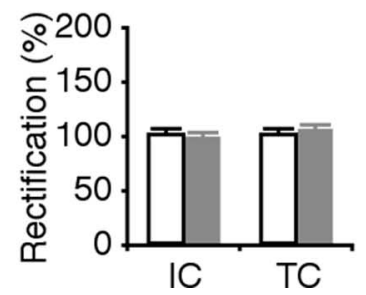

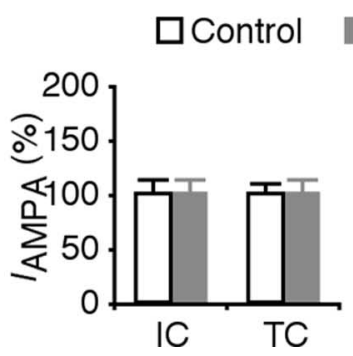

GluR1ct-GFP

Figure 2. Selective insertion of GluR1 into intracortical synapses requires whisker-dependent activity. A, Top, Evoked AMPA-R-mediated responses from intracortical (IC) and thalamocortical (TC) synapses recorded from nonexpressing (Ctrl) and GluR1-GFP-expressing (exp) neurons. Bottom left, AMPA responses in GluR1-GFP-expressing neurons from intracortical (Ctrl, $-17.7 \pm 3.5 \mathrm{pA}$; $\exp ,-17.8 \pm 2.1 \mathrm{pA} ; n=11 ; p=0.59)$ and thalamocortical (Ctrl, $-31.3 \pm 3.8 \mathrm{pA} ; \exp ,-31.6 \pm 5.0 \mathrm{pA} ; n=11 ; p=0.93)$ synapses. Bottom right, Rectification of GluR1-GFP-expressing neurons from intracortical (Ctrl, $1.26 \pm 0.12 ; \exp , 1.99 \pm 0.39 ; n=11 ; p<0.005)$ and thalamocortical (Ctrl, $1.50 \pm 0.17 ; \exp , 1.61 \pm 0.17 ; n=11 ; p=0.68)$ synapses. $\boldsymbol{B}$, Top, Evoked AMPA-Rand NMDA-R-mediated responses from intracortical and thalamocortical synapses recorded from nonexpressing (Ctrl) and GluR1ct-GFP-expressing neurons. Bottom left, AMPA responses in GluR1ct-GFP-expressing neurons of rats from intracortical (Ctrl, $-23.0 \pm 2.2 \mathrm{pA}$; exp, $-16.0 \pm 2.0 \mathrm{pA} ; n=16 ; p<0.005)$ and thalamocortical (Ctrl, $-19.7 \pm 2.3 \mathrm{pA} ;$ exp, $-18.7 \pm 2.6 \mathrm{pA}$; $n=16 ; p=0.57$ ) synapses, and GluR1ct-GFP-expressing neurons of wild-type (WT) mice (Ctrl, $-24.4 \pm 2.6 \mathrm{pA}$; exp, $-18.5 \pm 1.8 \mathrm{pA} ; n=13 ; p<0.005)$ and GluR1 knock-out (K0) mice (Ctrl, $-26.2 \pm 2.9 \mathrm{pA} ; \exp ,-27.4 \pm 3.6 \mathrm{pA} ; n=13 ; p=0.75)$ from intracortical synapses. Bottom right, NMDA responses in GluR1ct-GFP-expressing neurons of rats from intracortical (Ctrl, $32.5 \pm$ $3.9 \mathrm{pA} ; \exp , 30.8 \pm 3.3 \mathrm{pA} ; n=16 ; p=0.61)$ and thalamocortical (Ctrl, $35.7 \pm 5.7 \mathrm{pA} ; \exp , 35.0 \pm 3.5 \mathrm{pA} ; n=16 ; p=0.99)$ synapses, and GluR1ct-GFP-expressing neurons of WT mice (Ctrl, $38.5 \pm 2.6 \mathrm{pA}$; exp, $36.4 \pm 2.9 \mathrm{pA} ; n=13 ; p=0.13)$ and GluR1 KO mice (Ctrl, $42.7 \pm 4.3 \mathrm{pA}$; exp, $44.2 \pm 4.3 \mathrm{pA} ; n=13 ; p=0.22)$ from intracortical synapses. C, Top, Evoked AMPA-R-mediated responses from intracortical and thalamocortical synapses recorded from nonexpressing (Ctrl) and GluR1-GFP-expressing neurons from rats with whiskers trimmed during expression. Bottom left, AMPA responses in GluR1-GFP-expressing neurons from intracortical (Ctrl, $-20.5 \pm 2.4 \mathrm{pA} ; \exp ,-20.3 \pm 3.0 \mathrm{pA} ; n=13 ; p=0.86)$ and thalamocortical (Ctrl, $-18.3 \pm 3.1 \mathrm{pA} ;$ exp, $-18.8 \pm$ $2.7 \mathrm{pA} ; n=13 ; p=0.86$ ) synapses. Bottom right, Rectification of GluR1-GFP-expressing neurons from intracortical (Ctrl, $1.43 \pm 0.08 ; \exp , 1.39 \pm 0.09 ; n=13 ; p=0.86$ ) and thalamocortical ( $C$ trl, $1.45 \pm 0.11 ; \exp , 1.49 \pm 0.12 ; n=13 ; p=0.86$ ) synapses. D. Top, Evoked AMPA-R- and NMDA-R-mediated responses from intracortical and thalamocortical synapses recorded from nonexpressing (Ctrl) and GluR1ct-GFP-expressing neurons from rats with whiskers trimmed during expression. Bottom left, AMPA responses in GluR1ct-GFP-expressing neurons from intracortical $(\mathrm{Ctrl},-20.0 \pm 3.2 \mathrm{pA} ; \exp ,-20.2 \pm 2.5 \mathrm{pA} ; n=16 ; p=0.68)$ and thalamocortical ( $(\mathrm{trl},-30.6 \pm 2.8 \mathrm{pA} ; \exp ,-23.8 \pm 3.4 \mathrm{pA} ; n=16 ; p=0.88)$ synapses. Bottom right, NMDA responses in GluR1ct-GFP-expressing neurons from intracortical (Ctrl, $28.9 \pm 3.8 \mathrm{pA}$; $\exp , 30.9 \pm 5.3 \mathrm{pA} ; n=16 ; p=0.80)$ and thalamocortical (Ctrl, $34.5 \pm 4.3 \mathrm{pA} ; \exp , 34.6 \pm 6.0 \mathrm{pA} ; n=16 ; p=0.96)$ synapses. AMPA-R- and NMDA-R-mediated current amplitudes and SEs were normalized to average values from control cells. ${ }^{*} p<0.05$ (Wilcoxon's test).

tion efficacy ( $>85 \%$ of neurons) were isolated immediately before homogenization. Membranes were blotted with anti-GluR1 (1:8000; Millipore Bioscience Research Reagents) and anti-GluR4 (1:5000; Millipore Bioscience Research Reagents) and quantified by chemiluminescence and densitometric scanning of the films under linear exposure conditions as described previously (Zhu et al., 2000; McCormack et al., 2006). Electrophysiology. Simultaneous whole-cell in vitro recordings were obtained from pairs of nearby infected and noninfected layer 4 stellate neurons from thalamocortical slices and large tufted layer 5 pyramidal neurons from cortical layer 1 input-layer 5 cell slices (Zhu, 2000; Zhu et al., 2000; Larkum and Zhu, 2002), under visual guidance using fluorescence and transmitted light illumination, using two Axopatch-200B amplifiers (Molecular Devices). Bath solution $\left(33 \pm 1.5^{\circ} \mathrm{C}\right)$ contained the following (in mM): $125 \mathrm{NaCl}, 2.5 \mathrm{KCl}, 2 \mathrm{CaCl}_{2}, 1 \mathrm{MgCl}_{2}, 25 \mathrm{NaHCO}_{3}$, 

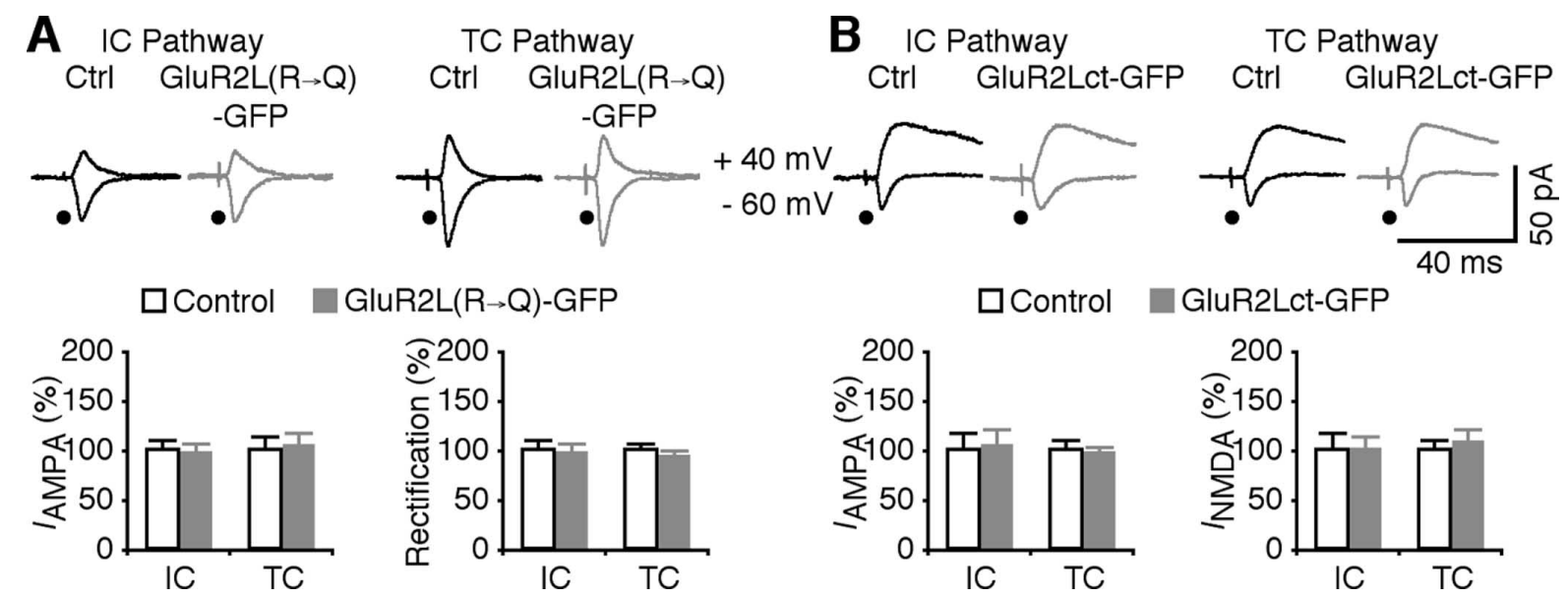

GluR2Lct-GFP

Figure 3. GluR2L does not mediate cortical transmission. $A$, Top, Evoked AMPA-R-mediated responses from intracortical (IC) and thalamocortical (TC) synapses recorded from nonexpressing (Ctrl) and GluR2L $(R \rightarrow Q)$-GFP-expressing (exp) neurons. Bottom left, AMPA responses in GluR2L $(R \rightarrow Q)$-GFP-expressing neurons from intracortical (Ctrl, $-21.3 \pm 2.4 \mathrm{pA}$; exp, $-20.5 \pm 2.3 \mathrm{pA} ; n=$ $11 ; p=0.79$ ) and thalamocortical (Ctrl, $-24.9 \pm 3.6 \mathrm{pA} ; \exp ,-25.9 \pm 3.8 \mathrm{pA} ; n=11 ; p=0.86)$ synapses. Bottom right, Rectification of GluR2L(R $\rightarrow 0$ ) -GFP-expressing neurons from intracortical (Ctrl, 1.66 $\pm 0.18 ; \exp , 1.58 \pm 0.17 ; n=11 ; p=0.53$ ) and thalamocortical (Ctrl, 1.66 $\pm 0.13 ; \exp , 1.56 \pm 0.12 ; n=21 ; p=0.42)$ synapses. B, Top, Evoked AMPA-R-and NMDA-R-mediated responses from intracortical and thalamocortical synapses recorded from nonexpressing (Ctrl) and GluR2Lct-GFP-expressing neurons. Bottom left, AMPA responses in GluR2Lct-GFP-expressing neurons from intracortical (Ctrl, $-15.7 \pm 2.7 \mathrm{pA} ; \exp ,-16.2 \pm 2.8 \mathrm{pA} ; n=13 ; p=0.53$ ) and thalamocortical (Ctrl, $-16.5 \pm 1.9 \mathrm{pA} ; \exp ,-16.0 \pm 1.0 \mathrm{pA} ; n=13 ; p=0.81)$ synapses. Bottom right, NMDA responses in GluR2LCt-GFP-expressing neurons from intracortical (Ctrl, 22.3 $\pm 3.6 \mathrm{pA} ; \exp , 22.6 \pm 3.1 \mathrm{pA} ; n=13 ; p=0.99$ ) and thalamocortical (Ctrl, 36.7 $\pm 3.1 \mathrm{pA} ; \exp , 28.9 \pm 3.5 ; n=13 ; p=0.88)$ synapses. AMPA-R-and NMDA-R-mediated current amplitudes and SEs were normalized to average values from control cells. ${ }^{*} p<0.05$ (Wilcoxon's test).

$1.25 \mathrm{NaH}_{2} \mathrm{PO}_{4}, 11$ glucose, and 0.1 picrotoxin 0.1 at $\mathrm{pH} 7.4$ (gassed with $5 \% \mathrm{CO}_{2} / 95 \% \mathrm{O}_{2}$ ). To block NMDA-Rs, when needed, 0.1 mM DL-AP-5 was added. To confirm the effectiveness of whisker trimming and TTX infusion on spontaneous activity, whole-cell in vivo recordings from layer 4 neurons were obtained in the virally infected barrel regions of anesthetized rats at $\sim 18 \mathrm{~h}$ after TTX infusion using an Axoclamp 2B amplifier as described previously (Zhu and Connors, 1999; Larkum and Zhu, 2002). After in vivo recordings, a small block of tissue containing the recorded cell was removed from the brain and immersion fixed with $4 \%$ paraformaldehyde in $0.1 \mathrm{M}$ phosphate buffer. The tissue blocks were sectioned $250 \mu \mathrm{m}$ thick, processed with the avidin-biotin-peroxidase method to confirm the morphology of recorded layer 4 stellate neurons (supplemental Fig. S2, available at www.jneurosci.org as supplemental material), which were subsequently drawn with the aid of a microscope equipped with a computerized reconstruction system (Neurolucida; MBF Bioscience). Patch recording pipettes (2-9 M 2 ) for current (voltage-clamp) recordings contained the following (in mM): 115 cesium methanesulfonate, $20 \mathrm{CsCl}, 10$ HEPES, $2.5 \mathrm{MgCl}_{2}, 4 \mathrm{Na}_{2} \mathrm{ATP}, 0.4$ $\mathrm{Na}_{3}$ GTP, 10 sodium phosphocreatine, 0.6 EGTA, and 0.1 spermine, at $\mathrm{pH}$ 7.25. Pipettes for voltage (current-clamp) recordings contained the following (in $\mathrm{mM}$ ): 115 potassium gluconate, 10 HEPES, $2 \mathrm{MgCl}_{2}, 2$ MgATP, $2 \mathrm{Na}_{2} \mathrm{ATP}, 0.3 \mathrm{Na}_{3} \mathrm{GTP}$, and $20 \mathrm{KCl}$ at $\mathrm{pH}$ 7.25. Junction potentials were not corrected. As with the previous studies (Gil et al., 1999; Zhu, 2000), stellate neurons in layer 4 and large tufted pyramidal neurons in layer 5 were targeted. In layer 4 , a small percentage of recorded neurons $(<3 \%)$ that fired short-duration action potentials (fast spiking), had a fast time constant, and/or displayed high frequency spontaneous events were not included in the analysis of this study. For layer 4 stellate neurons, monosynaptic EPSCs were elicited by electrical stimulation of cortical layer 4, 200-400 $\mu \mathrm{m}$ lateral to the recording sites (intracortical pathway), and in the thalamus (thalamocortical pathway). For layer 5 pyramidal neurons, monosynaptic EPSCs were elicited by electrical stimulation of cortical layer 5, $\sim 200-400 \mu \mathrm{m}$ lateral to the recording sites (intracortical pathway), and in layer $1, \sim 1000-1500 \mu \mathrm{m}$ lateral to the recording sites (L1 pathway). A surgical cut was made between the L1 stimulating electrode and targeted layer 5 neurons, from the middle layer 2 to the white matter, $\sim 400-600 \mu \mathrm{m}$ lateral from the neurons, which allowed a more selective activation of L1 synaptic inputs (Zhu, 2000). Synaptic AMPA and NMDA responses were averaged over 90 trials. The ratio of AMPA responses at -60 and $+40 \mathrm{mV}$ was used as an index of rectification (with 1.5 equivalent nonrectification). To minimize the effect from AMPA responses, the peak NMDA responses at $+40 \mathrm{mV}$ were measured after digital subtraction of estimated AMPA responses at +40 $\mathrm{mV}$. To isolate quantal synaptic events, extracellular $\mathrm{Sr}^{2+}$ was substituted for $\mathrm{Ca}^{2+}$, which made evoked transmitter release asynchronous and prolonged (Dodge et al., 1969; Abdul-Ghani et al., 1996; Oliet et al., 1996; Gil et al., 1999). In this condition, a single stimulus to either intracortical or thalamocortical axons evoked a number of small-amplitude synaptic currents, which had a frequency $(>5 \mathrm{~Hz})$ much higher than spontaneous EPSCs $(\sim 0.1-0.3 \mathrm{~Hz})$, and had sizes stable over the duration of the sampling period $(\sim 200-500 \mathrm{~ms})$ and well above the current noise (Figs. 1, 9) (cf. Gil et al., 1999). Thus, the individual quantal events with the known origin (i.e., from intracortical or thalamocortical synapses) could be easily isolated for analysis. The 10-90\% rise time and decay time constant using a single-exponential fitting were measured for evoked and asynchronous quantal EPSCs (Stern et al., 1992). The decay time constants of 20-50 asynchronous, quantal intracortical and thalamocortical events from single neurons were averaged and compared. DL-AP-5 at $0.1 \mathrm{~mm}$ was included in these experiments to remove NMDA-R-mediated EPSCs. All results were reported as mean \pm SEM, and statistical significances of the means $(p<0.05)$ were determined using Wilcoxon's and Mann-Whitney rank sum nonparametric tests for paired and unpaired samples, respectively.

\section{Results}

Intracortical and thalamocortical synapses possess different transmission kinetics

To investigate the regulation and functional impact of synaptic trafficking of distinct AMPA-Rs at different synapses in single neurons in layer 4, I developed a novel experimental approach that combined the in vitro thalamocortical brain slice preparation (Agmon and Connors, 1991), with an in vivo recombinant protein delivery technique (McCormack et al., 2006) (Fig. 1A) (see also Materials and Methods). GFP-tagged recombinant proteins were delivered to a small number of neurons $(\sim 5-50)$ in layer 4 of the rat barrel cortex by in vivo microinjection of a Sindbis virus that drives expression of recombinant proteins (McCormack et al., 2006; Hu et al., 2008). After $\sim 16$ h for expression, thalamocortical slices were prepared, and monosynaptic EPSCs of thalamocortical fiber origin and intracortical fiber origin were elicited as described previously (Gil et al., 1999). The evoked synaptic responses were compared between noninfected control 

A IC Pathway
TC Pathway
B IC Pathway
TC Pathway
Ctrl GluR4-GFP Ctrl GluR4-GFP
Ctrl GluR4ct-GFP
Ctrl GluR4ct-GFP
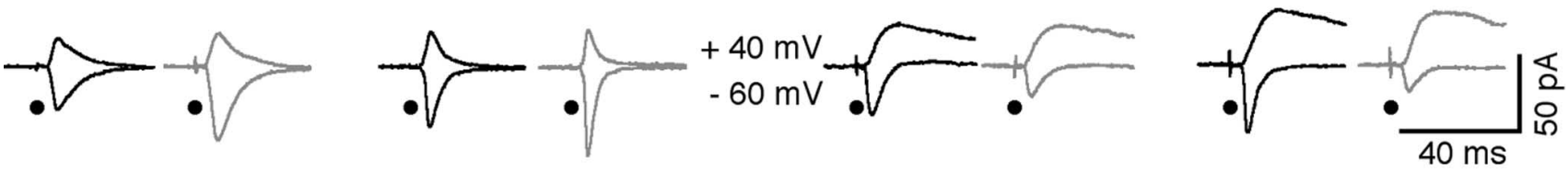

$\square$ Control GluR4-GFP
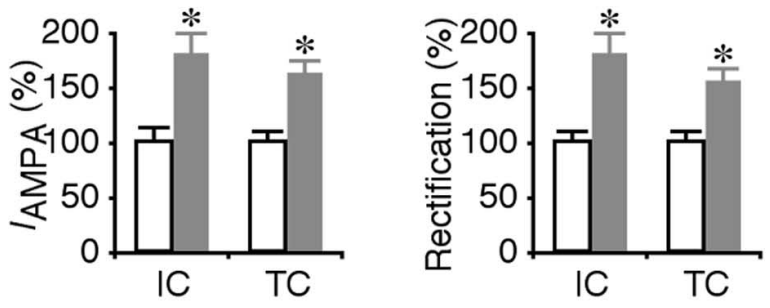

$\square$ Control

GluR4ct-GFP

C IC Pathway

Ctrl GluR4-GFP
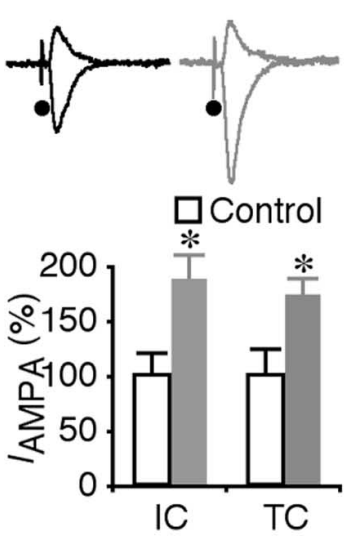

Ctrl GluR4-GFP
D IC Pathway Ctrl GluR4ct-GFP
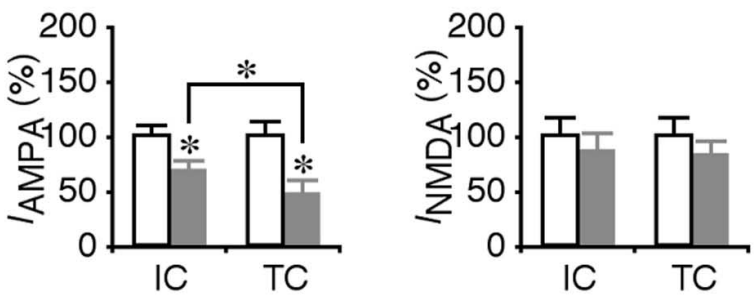

\section{With Whiskers Trimmed}

GluR4-GFP
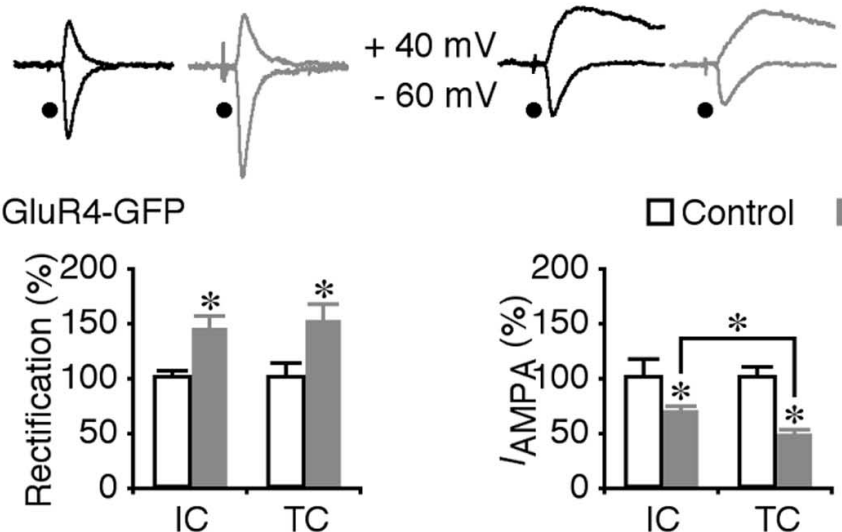

aControl

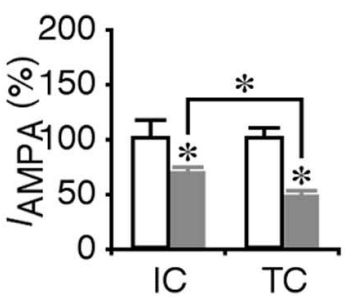

TC Pathway

Ctrl GluR4ct-GFP

\section{With Cortical Infusion of TTX}
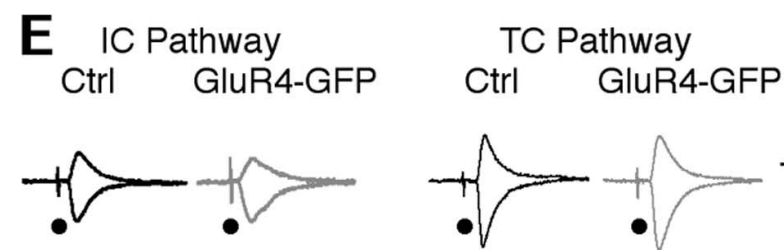

F IC Pathway

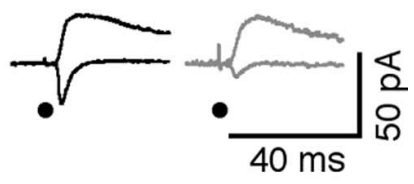

GluR4ct-GFP

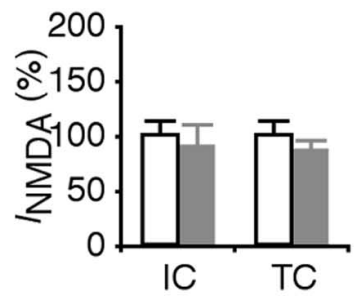

$\square$ Control GluR4-GFP
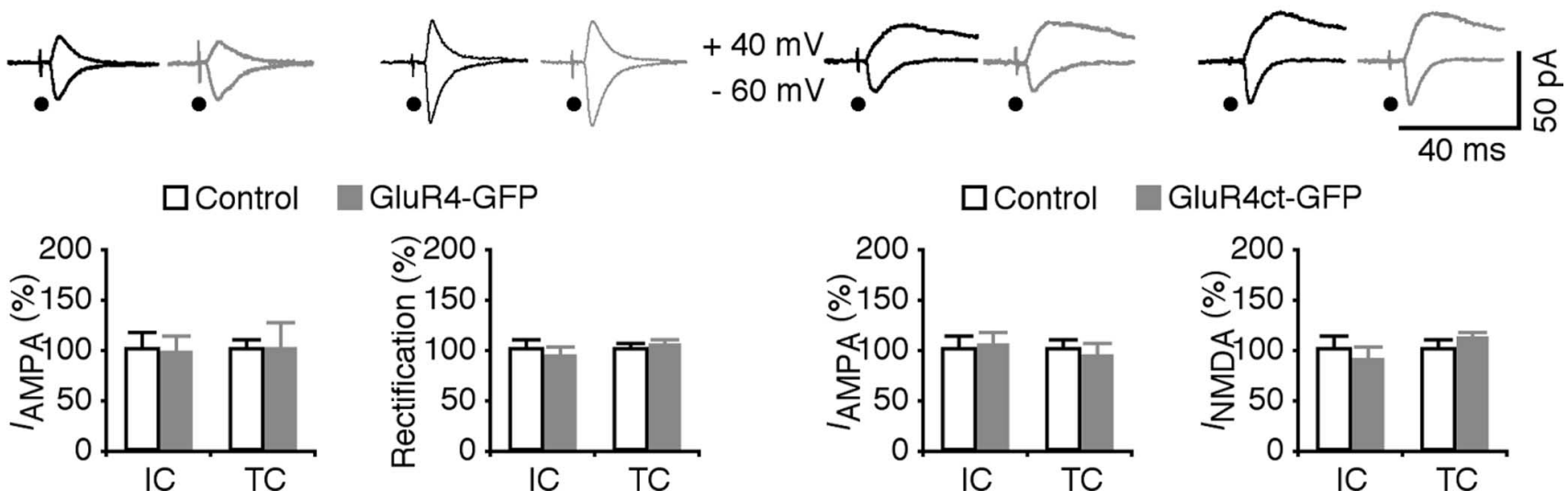

GluR4ct-GFP

Figure 4. Preferential insertion of GluR4 into thalamocortical synapses requires spontaneous activity. A, Top, Evoked AMPA-R-mediated responses from intracortical (IC) and thalamocortical (TC) synapses recorded from nonexpressing (Ctrl) and GluR4 -GFP-expressing (exp) neurons. Bottom left, AMPA responses in GluR4-GFP-expressing neurons from intracortical (Ctrl, $-14.9 \pm 2.4 \mathrm{pA}$; $\exp ,-26.4 \pm 3.0 \mathrm{pA} ; n=11 ; p<0.01)$ and thalamocortical (Ctrl, $-22.2 \pm 2.5 \mathrm{pA} ; \exp ,-35.6 \pm 3.6 \mathrm{pA} ; n=11 ; p<0.05)$ synapses. Bottom right, Rectification of GluR4-GFP-expressing neurons from intracortical (Ctrl, $1.32 \pm 0.15 ; \exp , 2.34 \pm 0.32 ; n=11 ; p<0.05$ ) and thalamocortical (Ctrl, $1.27 \pm 0.13 ; \exp , 1.96 \pm 0.17 ; n=11 ; p<0.01)$ synapses. $\boldsymbol{B}$, Top, Evoked AMPA-Rand NMDA-R-mediated responses from intracortical and thalamocortical synapses recorded from nonexpressing (Ctrl) and GluR4ct-GFP-expressing neurons. Bottom left, (Figure legend continues.) 
neurons and nearby infected neurons, which were identified by GFP fluorescence (Fig. 1A). As with previous studies (Gil et al., 1999; Castro-Alamancos, 2002), paired-pulse stimuli evoked facilitating responses in the intracortical pathway and depressing responses in the thalamocortical pathway in expressing and nearby nonexpressing neuron pairs (Fig. $1 B, C$ ).

Interestingly, in control nonexpressing neurons, the evoked EPSCs from intracortical synapses seemed to have a longer time course than those from thalamocortical synapses. Statistical analysis showed that, in normal layer 4 neurons, the rise times (intracortical, $1.87 \pm 0.12 \mathrm{~ms}$; thalamocortical, $1.52 \pm 0.12 \mathrm{~ms} ; n=18$; $p<0.05$ ) and decay time constants (intracortical, $5.70 \pm 0.47 \mathrm{~ms}$; thalamocortical, $3.91 \pm 0.32 \mathrm{~ms} ; n=18 ; p<0.005)$ of the evoked EPSCs from intracortical synapses were significantly longer than those from thalamocortical synapses (Fig. $1 B, C$ ). It is important to make a direction comparison of the kinetics of quantal events from thalamocortical and intracortical synapses, which requires defining the origins of spontaneous synaptic events in layer 4 stellate neurons. One way to achieve this is to induce asynchronous release by substituting extracellular $\mathrm{Ca}^{2+}$ with $\mathrm{Sr}^{2+}$, which makes evoked transmitter release asynchronous and prolonged and thus isolates single quantal events (Dodge et al., 1969; AbdulGhani et al., 1996; Oliet et al., 1996; Gil et al., 1999). In the

\section{$\leftarrow$}

(Figure legend continued.) AMPA responses in GluR4ct-GFP-expressing neurons from intracortical (Ctrl, $-24.8 \pm 2.9 \mathrm{pA} ; \exp ,-16.9 \pm 2.6 \mathrm{pA} ; n=15 ; p<0.005)$ and thalamocortical (Ctrl, $-25.5 \pm 3.7 \mathrm{pA}$; exp, $-12.2 \pm 3.1 \mathrm{pA} ; n=15 ; p<0.005)$ synapses. Bottom right, NMDA responses in GluR4ct-GFP-expressing neurons from intracortical (Ctrl, $35.7 \pm 5.9 \mathrm{pA}$; $\exp , 31.0 \pm 5.6 \mathrm{pA} ; n=15 ; p=0.31)$ and thalamocortical (Ctrl, $38.4 \pm 6.4 \mathrm{pA} ; \exp , 31.9 \pm$ $4.6 ; n=15 ; p=0.33$ ) synapses. Note that the depression at intracortical synapses was significantly smaller than that at thalamocortical synapses $(n=15 ; p<0.005)$. C, Top, Evoked AMPA-R-mediated responses from intracortical (IC) and thalamocortical (TC) synapses recorded from nonexpressing (Ctrl) and GluR4-GFP-expressing neurons from rats with whiskers trimmed during expression. Bottom left, AMPA responses in GluR4-GFP-expressing neurons from intracortical (Ctrl, $-15.5 \pm 3.2 \mathrm{pA} ; \exp ,-29.0 \pm 3.7 \mathrm{pA} ; n=12 ; p<0.005)$ and thalamocortical (Ctrl, $-21.5 \pm 5.1 \mathrm{pA} ; \exp ,-36.6 \pm 4.2 \mathrm{pA} ; n=12 ; p<0.01)$ synapses. Bottom right, Rectification of GluR4 -GFP-expressing neurons from intracortical (Ctrl, $1.38 \pm$ $0.09 ; \exp , 1.95 \pm 0.20 ; n=12 ; p<0.01)$ and thalamocortical (Ctrl, $1.40 \pm 0.20 ; \exp , 2.12 \pm$ $0.24 ; n=12 ; p<0.01$ ) synapses. $\boldsymbol{D}$, Top, Evoked AMPA-R- and NMDA-R-mediated responses from intracortical and thalamocortical synapses recorded from nonexpressing (Ctrl) and GluR4ct-GFP-expressing neurons from rats with whiskers trimmed during expression. Bottom left, AMPA responses in GluR4ct-GFP-expressing neurons from intracortical (Ctrl, $-20.9 \pm 3.4$ $\mathrm{pA} ; \exp ,-13.9 \pm 2.1 \mathrm{pA} ; n=13 ; p<0.01)$ and thalamocortical (Ctrl, $-26.0 \pm 2.6 \mathrm{pA} ; \exp$, $-11.8 \pm 1.7 \mathrm{pA} ; n=13 ; p<0.005)$ synapses. Bottom right, NMDA responses in GluR4ctGFP-expressing neurons from intracortical ( $(\mathrm{Ctrl}, 27.0 \pm 4.3 \mathrm{pA}$; $\exp , 24.5 \pm 5.4 \mathrm{pA} ; n=13$; $p=0.55)$ and thalamocortical (Ctrl, $31.7 \pm 4.6 \mathrm{pA} ; \exp , 27.1 \pm 3.8 ; n=13 ; p=0.51)$ synapses. Note that the depression at intracortical synapses was significantly smaller than that at thalamocortical synapses (IC, $28.4 \pm 7.5 \%$; TC, $53.7 \pm 5.5 \% ; n=13 ; p<0.005)$. $\boldsymbol{E}$, Top, Evoked AMPA-R-mediated responses from intracortical and thalamocortical synapses recorded from nonexpressing (Ctrl) and GluR4 -GFP-expressing neurons from rats with cortical infusion of TTX during expression. Bottom left, AMPA responses in GluR4 -GFP-expressing neurons from intracortical (Ctrl, $-23.7 \pm 4.1 \mathrm{pA} ; \exp ,-23.3 \pm 3.7 \mathrm{pA} ; n=11 ; p=0.93)$ and thalamocortical (Ctrl, $-20.6 \pm 3.4 \mathrm{pA}$; $\exp ,-20.9 \pm 5.8 \mathrm{pA} ; n=11 ; p=0.42$ ) synapses. Bottom right, Rectification of GluR4 -GFP-expressing neurons from intracortical (Ctrl, $1.50 \pm 0.13$; exp, $1.41 \pm 0.13 ; n=11 ; p=0.42$ ) and thalamocortical (Ctrl, $1.41 \pm 0.12 ; \exp , 1.48 \pm 0.10 ; n=$ $11 ; p=0.59)$ synapses. $\boldsymbol{F}$, Top, Evoked AMPA-R- and NMDA-R-mediated responses from intracortical and thalamocortical synapses recorded from nonexpressing (Ctrl) and GluR4ct-GFPexpressing neurons from rats with cortical infusion of TTX during expression. Bottom left, AMPA responses in GluR4ct-GFP-expressing neurons from intracortical (Ctrl, $-21.0 \pm 3.0 \mathrm{pA}$; exp, $-21.8 \pm 3.0 \mathrm{pA} ; n=15 ; p=0.87)$ and thalamocortical (Ctrl, $-21.9 \pm 2.3 \mathrm{pA}$; exp, $-20.7 \pm 2.8 \mathrm{pA} ; n=15 ; p=0.91)$ synapses. Bottom, Right, NMDA responses in GluR4ctGFP-expressing neurons from intracortical ( $(\mathrm{Ctrl}, 25.0 \pm 3.7 \mathrm{pA} ; \exp , 22.7 \pm 2.9 \mathrm{pA} ; n=15$; $p=0.69)$ and thalamocortical (Ctrl, $30.1 \pm 2.9$ pA; $\exp , 33.0 \pm 2.1 ; n=15 ; p=0.53)$ synapses. AMPA-R- and NMDA-R-mediated current amplitudes and SEs were normalized to average values from control cells. ${ }^{*} p<0.05$ (Wilcoxon's test). presence of $\mathrm{Sr}^{2+}$, low-frequency (at $0.1 \mathrm{~Hz}$ ) stimulation of either thalamocortical or intracortical fibers evoked a cluster of highfrequency $(>5 \mathrm{~Hz})$, small-amplitude, isolated synaptic currents that lasted for up to $500 \mathrm{~ms}$ (Fig. 1B). As in the previous report (Gil et al., 1999), these small asynchronous synaptic events could be easily isolated from the baseline, benefiting from the compact structure of layer 4 stellate neurons and the strong unitary synaptic inputs they receive (Feldmeyer et al., 1999; Cruikshank et al., 2007). Analysis showed that the rise times (intracortical, $0.78 \pm 0.03 \mathrm{~ms}$; thalamocortical, $0.63 \pm 0.03 \mathrm{~ms} ; n=20 ; p<$ 0.005 ) and decay time constants (intracortical, $3.16 \pm 0.14 \mathrm{~ms}$; thalamocortical, $2.49 \pm 0.11 \mathrm{~ms} ; n=20 ; p<0.0005)$ of quantal events from intracortical synapses were longer than those from thalamocortical synapses (Fig. $1 B, C$ ). Given that the intracortical and thalamocortical fibers form synapses evenly along the dendrites of layer 4 stellate neurons (White and Rock, 1980; White and Keller, 1989), these results suggest that thalamocortical synapses are enriched with AMPA-Rs with fast kinetics (e.g., GluR4containing AMPA-Rs) and/or sparse with AMPA-Rs with slow kinetics (e.g., GluR1-containing AMPA-Rs) (Mosbacher et al., 1994; Geiger et al., 1995; Jonas, 2000). These findings inspired additional experiments to investigate the differential contributions of distinct AMPA-Rs, e.g., GluR1- and GluR4-containing AMPA-Rs, in intracortical and thalamocortical transmission of layer 4 neurons (supplemental Fig. S3, available at www.jneurosci. org as supplemental material).

\section{GluR1 traffics selectively into intracortical synapses}

Previous immunocytochemistry studies have shown that GluR1 is expressed in cortical layer 4 neurons (Petralia and Wenthold, 1992; Martin et al., 1993). To determine whether GluR1 mediates intracortical and thalamocortical transmission, the evoked synaptic responses in nearby pairs of GluR1-GFP-expressing and nonexpressing neurons in layer 4 were compared (Fig. 2). This GluR1-GFP is electrophysiologically "tagged," and synaptic delivery of this receptor results in enhanced rectification of transmission (Hayashi et al., 2000; Zhu et al., 2002; McCormack et al., 2006; Kielland et al., 2009). The rectification of AMPA responses from intracortical synapses, but not from thalamocortical synapses, was enhanced in GluR1-GFP-expressing neurons compared with nearby nonexpressing neurons (Fig. 2A), indicating that GluR1-GFP was selectively inserted into intracortical synapses but not thalamocortical synapses.

To confirm that endogenous GluR1-containing AMPA-Rs mediate intracortical synaptic transmission, the GFP-tagged cytoplasmic termini of GluR1, GluR1ct-GFP, which functions as a dominant-negative form to selectively block synaptic trafficking of endogenous GluR1-containing AMPA-Rs (Kolleker et al., 2003; Qin et al., 2005; Hu et al., 2008; Kielland et al., 2009), was expressed in layer 4 stellate neurons. Compared with nearby nonexpressing neurons, AMPA responses from intracortical synapses, but not thalamocortical synapses, were depressed by $\sim 30 \%$ in GluR1ct-GFP-expressing neurons (Fig. 2 B). NMDA responses were not different between GluR1ct-GFP-expressing and nonexpressing neurons (Fig. $2 B$ ), suggesting a postsynaptic mechanism. As a control, GluR1ct-GFP was also expressed in wild-type and GluR1 knock-out mice. AMPA responses from intracortical synapses were depressed in GluR1ct-GFPexpressing neurons of wild-type mice but not GluR1 knock-out mice (Fig. 2B). Together, these results indicate that GluR1containing AMPA-Rs mediate $\sim 30 \%$ intracortical transmission but do not mediate thalamocortical transmission.

GluR2L is not expressed in the rodent cortex (Kolleker et al., 
2003). As a control, GluR2L(R $\rightarrow$ Q)-GFP was expressed in layer 4 stellate neurons. In this construct, the $\mathrm{R} \rightarrow \mathrm{Q}$ mutation is generated at its pore region to make it electrophysiologically tagged or rectified (Kolleker et al., 2003; Qin et al., 2005). Neurons expressing GluR2L $(\mathrm{R} \rightarrow \mathrm{Q})-\mathrm{GFP}$ had the same AMPA responses from intracortical and thalamocortical synapses as nearby nonexpressing neurons (Fig. 3A). Expression of GFP-tagged cytoplasmic termini of GluR2L, GluR2Lct-GFP, which functions as a dominant-negative form, selectively blocks synaptic trafficking of endogenous GluR2L-containing AMPA-Rs (Kolleker et al., 2003; Qin et al., 2005). Neurons expressing GluR2Lct-GFP had the same AMPA and NMDA responses from intracortical and thalamocortical synapses as nearby nonexpressing neurons (Fig. $3 B$ ). These results suggest that GluR2L does not mediate transmission in layer 4 stellate neurons, and expressing recombinant GluR-GFP has no nonspecific effect on transmission in layer 4 stellate neurons.

Strong and/or sensory experience-dependent synaptic activity is required for synaptic insertion of GluR1-containing AMPA-Rs in thalamocortical neurons, hippocampal CA1, and cortical layer 2/3 pyramidal neurons (Zhu et al., 2002; Takahashi et al., 2003; McCormack et al., 2006; Hu et al., 2008; Kielland et al., 2009). To determine whether selective delivery of GluR1 into intracortical synapses in layer 4 neurons of the barrel cortex requires experience-dependent activity, the somatosensory experiencedependent activity in these neurons was blocked by trimming all large whiskers on the contralateral face. This manipulation, which spared spontaneous synaptic activity in layer 4 neurons $(n=7)$ (supplemental Fig. S2 A, available at www.jneurosci.org as supplemental material), prevented the enhancement of rectification of AMPA responses from intracortical synapses in GluR1-GFP-expressing neurons and blocked the depression of AMPA responses from intracortical synapses in GluR1ct-GFPexpressing neurons (Fig. 2C,D). These results indicate that experience-dependent activity drives GluR1-containing AMPA-Rs into intracortical synapses in layer 4 stellate neurons. Because synaptic delivery of GluR1 is crucial for long-term potentiation (LTP) and experience-dependent plasticity (Hayashi et al., 2000; Kolleker et al., 2003; Takahashi et al., 2003; Qin et al., 2005; McCormack et al., 2006; Hu et al., 2008), these results are consistent with the notion that LTP and experience-dependent plasticity are present at intracortical synapses but absent at thalamocortical synapses of mature cortical neurons (Crair and Malenka, 1995; Isaac et al., 1997; Hardingham and Fox, 2006; Cheetham et al., 2007; Wright et al., 2008).

\section{GluR4 traffics preferentially into thalamocortical synapses}

GluR4 is expressed in cortical layer 4 (Petralia and Wenthold, 1992). Thus, GluR4-containing AMPA-Rs could mediate intracortical and/or thalamocortical transmission in layer 4 neurons. To test this idea, the GFP-tagged GluR4, GluR4-GFP, which is electrophysiologically tagged or rectified and behaves like endogenous heteromeric GluR4-containing AMPA-Rs during synaptic trafficking (Zhu et al., 2000; McCormack et al., 2006; Hu et al., 2008), was expressed in layer 4 stellate neurons. Layer 4 neurons expressing GluR4-GFP had enhanced rectification and amplitude of AMPA responses from intracortical and thalamocortical synapses (Fig. 4A), indicating synaptic insertion of GluR4-GFP at both intracortical and thalamocortical synapses.

To determine whether endogenous GluR4-containing AMPA-Rs mediate intracortical and thalamocortical transmission, the GFP-tagged cytoplasmic termini of GluR4, GluR4ctGFP, was expressed in layer 4 stellate neurons. Expression of
GluR4ct-GFP, which functions as a dominant-negative form, selectively blocks synaptic trafficking of endogenous GluR4containing AMPA-Rs (Zhu et al., 2000; Kolleker et al., 2003; McCormack et al., 2006). Layer 4 neurons expressing GluR4ct-GFP had depressed AMPA responses from both intracortical and thalamocortical synapses (Fig. $4 B$ ). NMDA responses were not different between GluR4ct-GFP-expressing and nonexpressing neurons (Fig. $4 B$ ). Interestingly, the depression at intracortical synapses $(\sim 30 \%)$ was significantly smaller than that at thalamocortical synapses $(\sim 50 \%)$ in GluR4ct-GFP-expressing neurons (Fig. 4B). These results indicate that GluR4-containing AMPA-Rs traffic into both intracortical and thalamocortical synapses, and they mediate a larger proportion of thalamocortical transmission than intracortical transmission.

Spontaneous synaptic activity is sufficient to drive GluR4containing AMPA-Rs into synapses of hippocampal CA1 and cortical layer 2/3 pyramidal neurons (Zhu et al., 2000; McCormack et al., 2006; Hu et al., 2008). To determine which form(s) of synaptic activity drive GluR4 into intracortical and thalamocortical synapses in cortical layer 4 stellate neurons, I either trimmed all large whiskers on the contralateral face to block sensory experience-dependent synaptic activity or infused TTX into layer 4 during the expression to also block spontaneous synaptic activity. Trimming whiskers blocked neither the enhanced rectification, nor amplitude of AMPA responses in GluR4-GFP-expressing neurons, nor the depressed AMPA responses in GluR4ct-GFP-expressing neurons (Fig. 4C,D). In contrast, cortical infusion of TTX, which blocked action potential-dependent synaptic activity in layer 4 stellate neurons (supplemental Fig. S2 B, available at www.jneurosci.org as supplemental material), prevented the enhancement of rectification and amplitude of AMPA responses in GluR4-GFP-expressing neurons and blocked the depression of AMPA responses in GluR4ct-GFPexpressing neurons (Fig. 4E,F). These results indicate that experience-independent spontaneous activity drives GluR4containing AMPA-Rs into intracortical and thalamocortical synapses.

\section{GluR2 traffics equally into both intracortical and thalamocortical synapses}

GluR2 is highly expressed in layer 4 neurons (Petralia and Wenthold, 1992; Martin et al., 1993). To examine the role of GluR2-containing AMPA-Rs in intracortical and thalamocortical transmission, a GFP-tagged GluR2 with the $\mathrm{R} \rightarrow \mathrm{Q}$ pore $\mathrm{mu}-$ tation, GluR2 $(\mathrm{R} \rightarrow \mathrm{Q})-\mathrm{GFP}$, which is electrophysiologically tagged and behaves like endogenous GluR2-containing AMPA-Rs during synaptic trafficking (Shi et al., 2001; Zhu et al., 2002), was expressed in layer 4 stellate neurons. Layer 4 neurons expressing GluR2 $(\mathrm{R} \rightarrow \mathrm{Q})-\mathrm{GFP}$ had enhanced rectification of AMPA responses from intracortical and thalamocortical synapses compared with nearby nonexpressing neurons (Fig. 5A), indicating synaptic insertion of GluR2 $(\mathrm{R} \rightarrow \mathrm{Q})-\mathrm{GFP}$ into both types of synapses. The amplitude of AMPA responses from intracortical and thalamocortical synapses of GluR2 $(\mathrm{R} \rightarrow \mathrm{Q})-\mathrm{GFP}$ expressing and nearby nonexpressing neurons was the same. These results are consistent with the findings that synaptic insertion of GluR2-containing AMPA-Rs is involved in synaptic AMPA-R exchange and/or cycling, two activity-independent replacement processes that maintain synaptic efficacy (McCormack et al., 2006; Kessels and Malinow, 2009).

To determine whether endogenous GluR2-containing AMPA-Rs mediate cortical transmission, the GFP-tagged cytoplasmic termini of GluR2, GluR2ct-GFP, which selectively blocks synaptic trafficking of endogenous GluR2-containing 

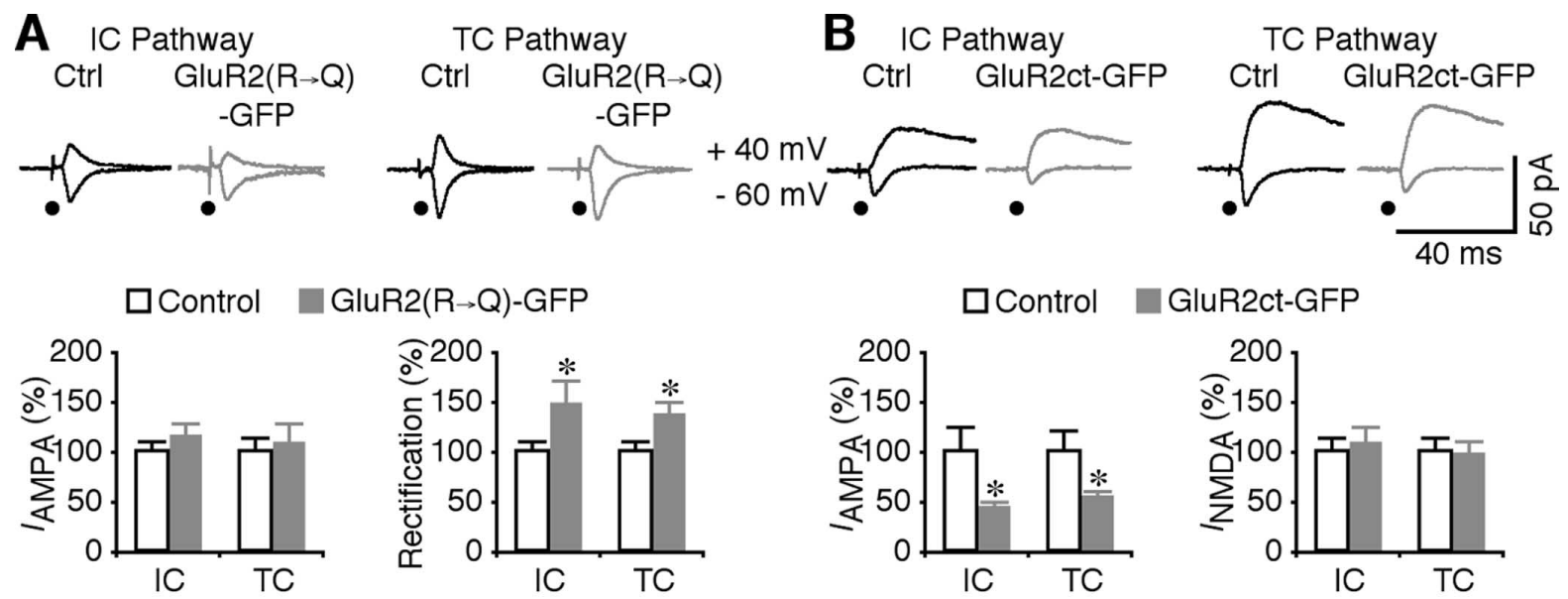

\section{With Cortical Infusion of TTX}
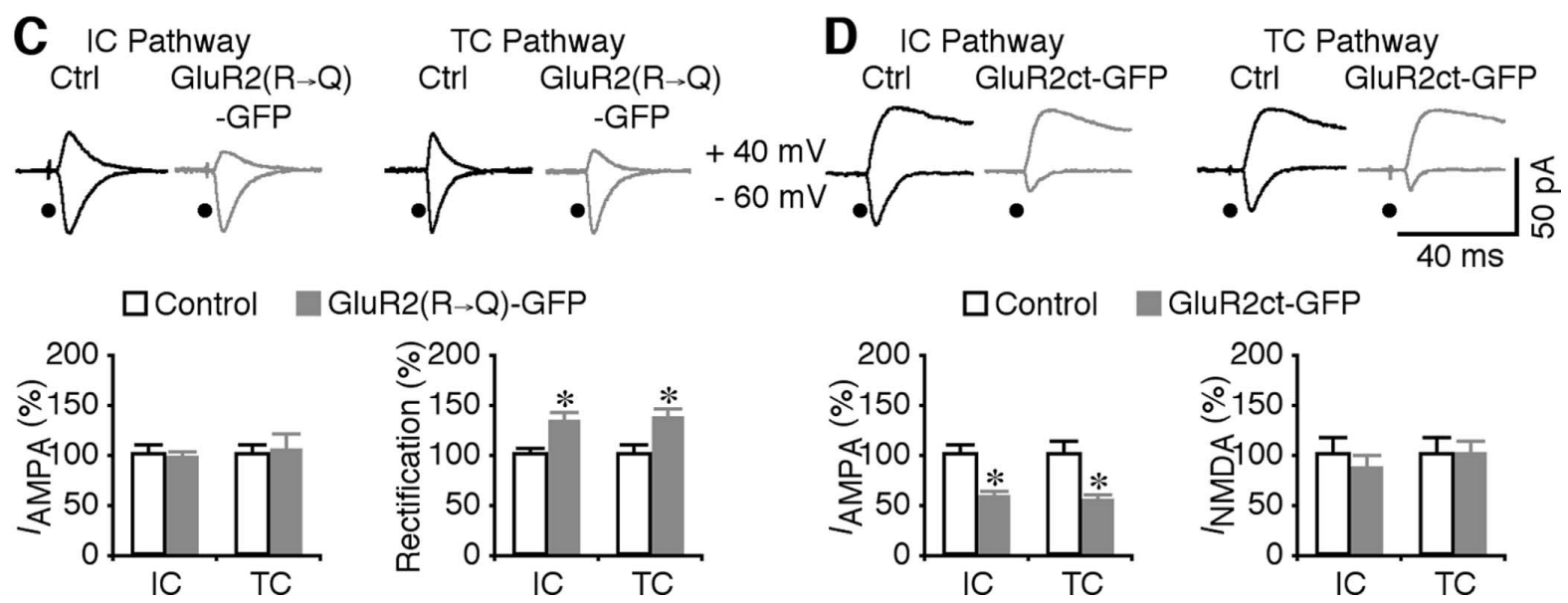

Figure 5. Equivalent insertion of GluR2 into intracortical and thalamocortical synapses requires no activity. $A$, Top, Evoked AMPA-R-mediated responses from intracortical (IC) and thalamocortical $(T C)$ synapses recorded from nonexpressing (Ctrl) and GluR2 $(R \rightarrow Q)-G F P$-expressing neurons. Bottom left, AMPA responses in GluR2(R $\rightarrow Q)$-GFP-expressing neurons from intracortical (Ctrl, $-21.0 \pm 2.3 \mathrm{pA} ; \exp ,-23.7 \pm 3.4 \mathrm{pA} ; n=11 ; p=0.51)$ and thalamocortical (Ctrl, $-24.1 \pm 3.8 \mathrm{pA}$; exp, $-25.9 \pm 5.5 \mathrm{pA} ; n=11 ; p=0.79)$ synapses. Bottom right, Rectification of GluR2 $(\mathrm{R} \rightarrow Q$ )-GFP-expressing neurons from intracortical (Ctrl, $1.33 \pm 0.07 ; \exp , 1.95 \pm 0.31 ; n=11 ; p<0.05)$ and thalamocortical (Ctrl, 1.21 $\pm 0.13 ; \exp , 1.64 \pm 0.12 ; n=11 ; p<0.005)$ synapses. $\boldsymbol{B}$, Top, Evoked AMPA-R- and NMDA-R-mediated responses from intracortical and thalamocortical synapses recorded from nonexpressing (Ctrl) and GluR2ct-GFP-expressing neurons. Bottom left, AMPA responses in GluR2ct-GFP-expressing neurons from intracortical (Ctrl, $-13.4 \pm 3.2 \mathrm{pA} ; \exp ,-6.0 \pm 0.8 \mathrm{pA} ; n=14 ; p<0.05)$ and thalamocortical (Ctrl, $-20.0 \pm 5.6 \mathrm{pA}$; exp, $-12.8 \pm 2.0 \mathrm{pA} ; n=13 ; p<0.05)$ synapses. Bottom right, NMDA responses in GluR2ct-GFP-expressing neurons from intracortical (Ctrl, $16.9 \pm 2.5 \mathrm{pA} ;$ exp, $18.1 \pm 3.0 \mathrm{pA} ; n=13 ; p=0.65)$ and thalamocortical (Ctrl, $28.5 \pm 3.7 \mathrm{pA}$; exp, $27.4 \pm 4.6 ; n=13 ; p=0.65)$ synapses. C, Top, Evoked AMPA-R-mediated responses from intracortical and thalamocortical synapses recorded from nonexpressing (Ctrl) and GluR2 ( $\rightarrow Q$ ) -GFP-expressing neurons from rats with cortical infusion of TTX during expression. Bottom left, AMPA responses in GluR2( $\rightarrow$ $\rightarrow$ )-GFP-expressing neurons from intracortical (Ctrl, $-30.3 \pm 3.6 \mathrm{pA}$; exp, $-29.4 \pm 2.2 \mathrm{pA} ; n=11 ; p=0.72)$ and thalamocortical (Ctrl, $-24.1 \pm 2.6 \mathrm{pA} ; \exp ,-24.7 \pm 4.5 \mathrm{pA} ; n=11 ; p=0.93)$ synapses. Bottom right, Rectification of GluR2 ( $\rightarrow Q$ ) -GFP-expressing neurons from intracortical (Ctrl, $1.48 \pm 0.10 ; \exp , 1.96 \pm 0.17 ; n=11 ; p<0.005)$ and thalamocortical (Ctrl, $1.43 \pm 0.13 ;$ exp, $1.94 \pm 0.14 ; n=$ $11 ; p<0.005)$ synapses. D, Top, Evoked AMPA-R- and NMDA-R-mediated responses from intracortical and thalamocortical synapses recorded from nonexpressing (Ctrl) and GluR2ct-GFPexpressing neurons from rats with cortical infusion of TTX during expression. Bottom left, AMPA responses in GluR2ct-GFP-expressing neurons from intracortical (Ctrl, $-21.6 \pm 2.7 \mathrm{pA}$; exp, $-12.5 \pm 1.5 \mathrm{pA} ; n=11 ; p<0.005)$ and thalamocortical synapses (Ctrl, $-24.6 \pm 3.9 \mathrm{pA} ; \exp ,-13.2 \pm 2.2 \mathrm{pA} ; n=11 ; p<0.005)$. Bottom right, NMDA responses in GluR2ct-GFP-expressing neurons from intracortical (Ctrl, $30.3 \pm 5.3 \mathrm{pA} ; \exp , 25.9 \pm 4.5 \mathrm{pA} ; n=11 ; p=0.42)$ and thalamocortical (Ctrl, $30.9 \pm 5.1 \mathrm{pA} ; \exp , 30.5 \pm 4.7 ; n=11 ; p=0.79)$ synapses. AMPA-R- and NMDA-R-mediated current amplitudes and SEs were normalized to average values from control cells. ${ }^{*} p<0.05$ (Wilcoxon's test).

AMPA-Rs (Kolleker et al., 2003; Qin et al., 2005), was expressed in layer 4 stellate neurons. Layer 4 neurons expressing GluR2ctGFP had reduced AMPA responses $(\sim 50 \%)$ from intracortical and thalamocortical synapses (Fig. 5B). NMDA responses did not differ between GluR2ct-GFP-expressing and nearby nonexpressing neurons (Fig. 5B). Together, the results indicate that GluR2-containing AMPA-Rs mediate 50\% intracortical and thalamocortical transmission.

Synaptic insertion of GluR2-containing AMPA-Rs requires no activity in hippocampal and cortical layer $2 / 3$ pyramidal neurons (McCormack et al., 2006; Kessels and Malinow, 2009). Con- sistent with these results, cortical infusion of TTX blocked neither the enhanced rectification in GluR2 $(\mathrm{R} \rightarrow \mathrm{Q})-\mathrm{GFP}$-expressing neurons nor the depressed AMPA responses in GluR2ct-GFPexpressing neurons in layer 4 (Fig. $5 C, D$ ). These results indicate that delivery of GluR2 into intracortical and thalamocortical synapses requires no synaptic activity.

\section{Distinct regulation of synaptic trafficking of GluR1 and GluR4}

The above data suggest that synaptic trafficking of GluR1 and GluR4 is synapse specific, and the levels of synaptic activity dif- 

A IC Pathway
TC Pathway
Ctrl GluR1-GFP
Ctrl GluR1-GFP
B IC Pathway
TC Pathway
Ctrl GluR4-GFP
Ctrl GluR4-GFP

12 hrs Expression

12 hrs Expression

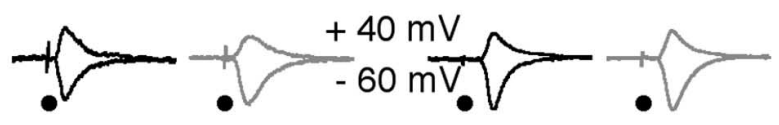

20 hrs Expression
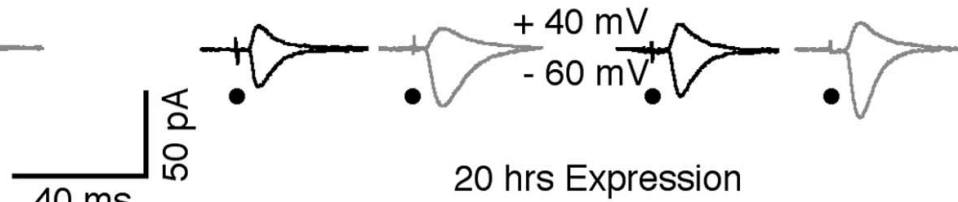

20 hrs Expression
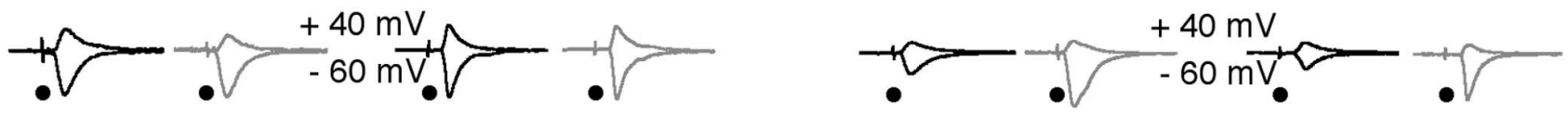

$\square$ Control-IC GluR1-GFP-IC
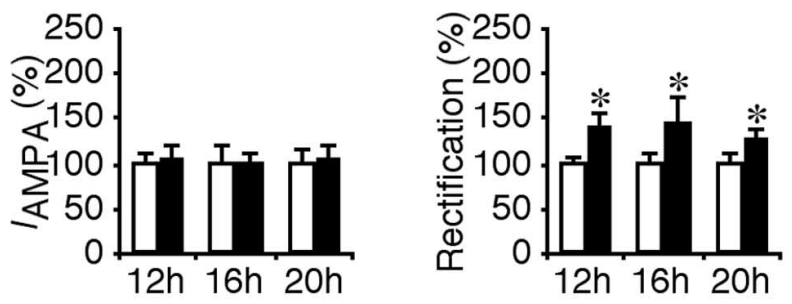

$\square$ Control-IC
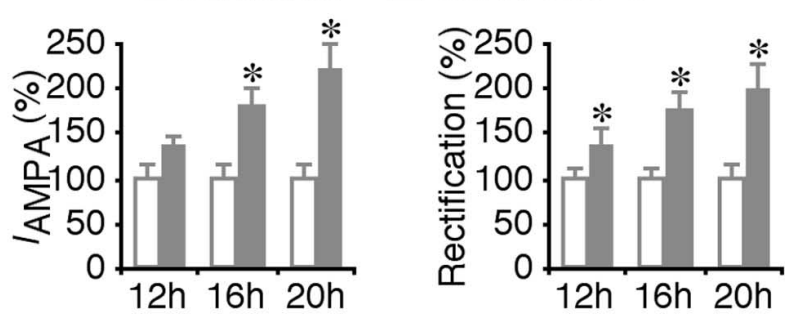

$\square$ Control-TC GluR1-GFP-TC

Control-TC GluR4-GFP-TC
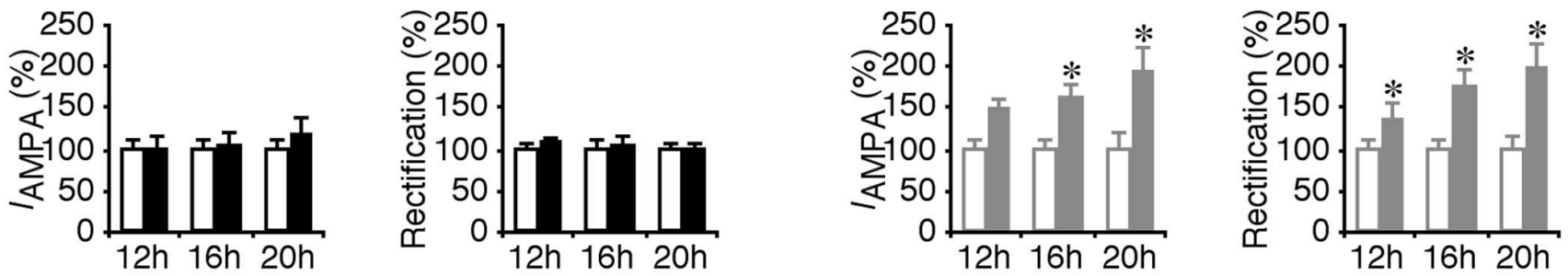

C anti-GluR1
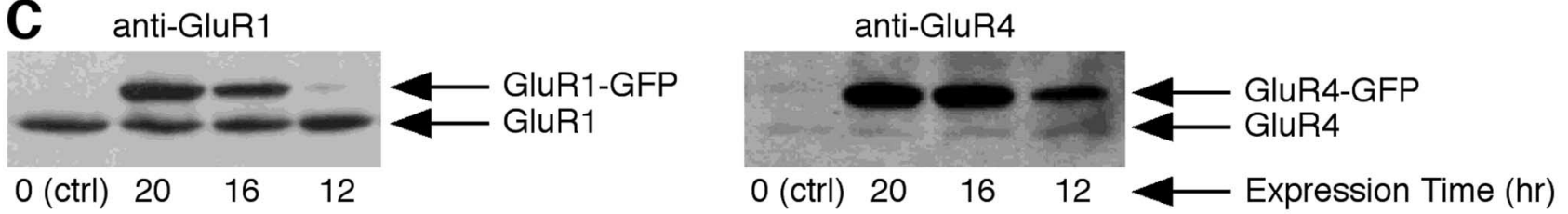

D

웅

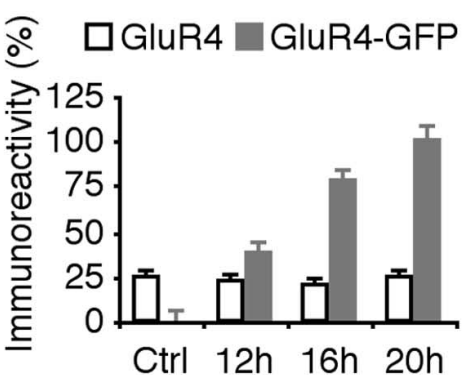

E $\square$ GluR1-TC a GluR1-IC O GluR4-TC GluR4-IC

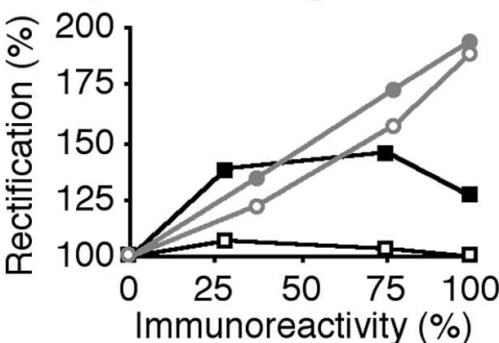

Figure 6. Expression level regulates synaptic insertion of GluR4 but not GluR1.A, Top, Evoked AMPA-R-mediated responses from intracortical (IC) and thalamocortical (TC) synapses recorded from nonexpressing (Ctrl) and GluR1-GFP-expressing (exp) neurons after 12 and $20 \mathrm{~h}$ of expression. Bottom left, From intracortical synapses, AMPA responses in GluR1-GFP-expressing neurons after $12 \mathrm{~h}$ $(\mathrm{Ctrl},-30.5 \pm 3.4 \mathrm{pA} ; \exp ,-31.7 \pm 4.7 \mathrm{pA} ; n=13 ; p=0.75), 16 \mathrm{~h}(\mathrm{Ctrl},-18.2 \pm 3.8 \mathrm{pA} ; \exp ,-18.0 \pm 2.4 \mathrm{pA} ; n=10 ; p=0.72)$ or $20 \mathrm{~h}(\mathrm{Ctrl},-23.9 \pm 4.3 \mathrm{pA} ; \exp ,-24.0 \pm 4.9 \mathrm{pA} ; n=$ $10 ; p=0.88)$ expression of GluR1-GFP, and from thalamocortical synapses, AMPA responses in GluR1-GFP-expressing neurons after $12 \mathrm{~h}(\mathrm{Ctrl},-29.8 \pm 3.7 \mathrm{pA} ; \exp ,-29.3 \pm 4.7 \mathrm{pA} ; n=13$; $p=0.92), 16 \mathrm{~h}(\mathrm{Ctrl},-32.4 \pm 4.0 \mathrm{pA} ; \exp ,-33.7 \pm 5.0 \mathrm{pA} ; n=10 ; p=0.88)$, or $20 \mathrm{~h}(\mathrm{Ctrl},-20.8 \pm 2.6 \mathrm{pA} ; \exp ,-23.6 \pm 5.0 \mathrm{pA} ; n=10 ; p=0.96)$ (Figure legend continues.) 
ferentially regulate synaptic trafficking of GluR1 and GluR4. To determine whether the protein expression level affects synaptic trafficking of GluR1- and GluR4-containing AMPA-Rs, synaptic responses were examined after viral expression of GluR1-GFP and GluR4-GFP for 12,16 , or $20 \mathrm{~h}$, each having the last $\sim 8 \mathrm{~h}$ expression set in the animals' awake period, which was required for synaptic delivery of GluR1 (Qin et al., 2005; Hu et al., 2008). Synaptic exchange of the newly delivered GluR1-GFP and GluR4-GFP is limited during these expression periods based on the previous study (McCormack et al., 2006). Neurons expressing GluR1-GFP for 12, 16, or $20 \mathrm{~h}$ had the same enhanced rectification of AMPA responses from intracortical synapses and the same AMPA responses from thalamocortical synapses compared with nearby nonexpressing neurons (Fig. 6A), suggesting no effect of expression time on synaptic delivery of GluR1-GFP at intracortical synapses. In contrast, neurons expressing GluR4GFP for 12,16 , or $20 \mathrm{~h}$ had progressively more enhanced amplitude and rectification of AMPA responses from both intracortical and thalamocortical synapses (Fig. $6 B$ ), suggesting more synaptic delivery of GluR4-GFP with increased expression times. Western blot analysis showed that the levels of GluR1-GFP and GluR4GFP expression increased with increased expression times, whereas the levels of endogenous GluR1 and GluR4 remained constant (Fig. 6C,D). Plotting the changes in rectification of AMPA responses in GluR4-GFP and GluR1-GFP expression

\footnotetext{
(Figure legend continued.) expression of GluR1-GFP. Bottom right, From intracortical synapses, rectification of GluR1-GFP-expressing neurons after $12 \mathrm{~h}$ (Ctrl, 1.37 \pm 0.11 ; exp, $1.91 \pm 0.25$; $n=13 ; p<0.005), 16 \mathrm{~h}(\mathrm{Ctrl}, 1.21 \pm 0.12 ; \exp , 1.78 \pm 0.34 ; n=10 ; p<0.01)$, or $20 \mathrm{~h}(\mathrm{Ctrl}$, $1.79 \pm 0.17 ; \exp , 2.27 \pm 0.24 ; n=10 ; p<0.01$ ) expression of GluR1-GFP, and from thalamocortical synapses, rectification of GluR1-GFP-expressing neurons after $12 \mathrm{~h}$ (Ctrl, $1.32 \pm 0.09 ; \exp , 1.41 \pm 0.08 ; n=13 ; p=0.31), 16 \mathrm{~h}(\mathrm{Ctrl}, 1.49 \pm 0.09 ; \exp , 1.45 \pm 0.17$ $n=10 ; p=0.72)$, or $20 \mathrm{~h}(\mathrm{Ctrl}, 1.58 \pm 0.14 ; \exp , 1.58 \pm 0.10 ; n=10 ; p=0.96)$ expression of GluR1-GFP. B, Top, Evoked AMPA-R-mediated responses from intracortical and thalamocortical synapses recorded from nonexpressing (Ctrl) and GluR4 -GFP-expressing neurons after 12 and $20 \mathrm{~h}$ of expression. Bottom left, From intracortical synapses, AMPA responses in GluR4GFP-expressing neurons after $12 \mathrm{~h}(\mathrm{Ctrl},-21.8 \pm 3.9 \mathrm{pA} ; \exp ,-28.8 \pm 3.0 \mathrm{pA} ; n=11 ; p=$ $0.18), 16 \mathrm{~h}$ (Ctrl, $-15.2 \pm 2.6 \mathrm{pA}$; exp, $-27.1 \pm 3.3 \mathrm{pA} ; n=10 ; p<0.05)$, or $20 \mathrm{~h}$ (Ctrl, $-15.3 \pm 2.3 \mathrm{pA} ; \exp ,-33.2 \pm 4.7 \mathrm{pA} ; n=10 ; p<0.01$ ) expression of GluR4 -GFP, and from thalamocortical synapses, AMPA responses in GluR4 -GFP-expressing neurons after $12 \mathrm{~h}$ (Ctrl, $-29.3 \pm 2.8 \mathrm{pA} ; \exp ,-41.3 \pm 4.8 \mathrm{pA} ; n=11 ; p=0.05), 16 \mathrm{~h}(\mathrm{Ctrl},-21.6 \pm 2.7 \mathrm{pA} ; \exp$, $-35.0 \pm 3.9 \mathrm{pA} ; n=10 ; p<0.05)$, or $20 \mathrm{~h}(\mathrm{Ctrl},-20.0 \pm 4.3 \mathrm{pA} ; \exp ,-38.8 \pm 5.6 \mathrm{pA} ; n=$ $12 ; p<0.05)$ expression of GluR4 -GFP. Bottom right, From intracortical synapses, rectification of GluR4-GFP-expressing neurons after $12 \mathrm{~h}(\mathrm{Ctrl}, 1.36 \pm 0.14$; $\exp , 1.85 \pm 0.26 ; n=11 ; p<$ $0.005), 16 \mathrm{~h}(\mathrm{Ctrl}, 1.40 \pm 0.14 ; \exp , 2.44 \pm 0.10 ; n=10 ; p<0.01)$, or $20 \mathrm{~h}(\mathrm{Ctrl}, 1.53 \pm 0.24$; exp, $2.97 \pm 0.54 ; n=10 ; p<0.005$ ) expression of GluR4-GFP, and from thalamocortical synapses, rectification of GluR4-GFP-expressing neurons after $12 \mathrm{~h}(\mathrm{Ctrl}, 1.27 \pm 0.12$; exp, $1.57 \pm 0.14 ; n=11 ; p<0.05), 16 \mathrm{~h}(\mathrm{Ctrl}, 1.24 \pm 0.14 ; \exp , 1.96 \pm 0.18 ; n=10 ; p<0.01)$, or $20 \mathrm{~h}$ (Ctrl, $1.24 \pm 0.08$; exp, $2.36 \pm 0.36 ; n=12 ; p<0.005$ ) expression of GluR4-GFP. AMPA-R- and NMDA-R-mediated current amplitudes and SEs were normalized to average values from control cells. ${ }^{*} p<0.05$ (Wilcoxon's test). C, Western blots of endogenous GluR1 and recombinant GluR1-GFP, and endogenous GluR4 and recombinant GluR4-GFP in control barrel cortical layer 4 tissues and tissues after $12 \mathrm{~h}, 16$ and $20 \mathrm{~h}$ of expression. Each lane was loaded with the same amount of protein $(60 \mu \mathrm{g})$. D, Left, Relative amounts of GluR1 and GluR1-GFP in control layer 4 tissues (GluR1, $71.2 \pm 6.8 \%$; GluR1-GFP, $0.2 \pm 0.7 \% ; n=9$ ), layer 4 tissues after $12 \mathrm{~h}$ (GluR1, 75.6 $\pm 5.8 \%$; GluR1-GFP, $28.4 \pm 6.6 \% ; n=9$ ), $16 \mathrm{~h}$ (GluR1,75.6 $\pm 5.8 \%$; GluR1-GFP, $28.4 \pm 6.6 \% ; n=9$ ), or $20 \mathrm{~h}$ (GluR1, $62.3 \pm 8.1 \%$; GluR1-GFP, $100.0 \pm 10.6 \%$; $n=9$ ) expression of GluR1-GFP. Right, Relative amounts of GluR4 and GluR4 -GFP in control layer 4 tissues (GluR4, $22.5 \pm 4.5 \%$; GluR4 -GFP, $0.8 \pm 6.6 \% ; n=10$ ), layer 4 tissues after $12 \mathrm{~h}$ (GluR4, 22.5 $\pm 4.5 \%$; GluR4-GFP, 37.8 $\pm 7.2 \% ; n=10$ ), $16 \mathrm{~h}$ (GluR4, $21.1 \pm 4.3 \%$; GluR4 GFP, $77.6 \pm 7.3 \% ; n=10)$, or $20 \mathrm{~h}$ (GluR4, $25.0 \pm 4.5 \%$; GluR4-GFP, $100.0 \pm 9.0 \% ; n=10$ ) expression of GluR4-GFP. The relative values and SEs were normalized to average amounts of GluR1GFP or GluR4-GFP from layer 4 tissues after $20 \mathrm{~h}$ of expression. $\boldsymbol{E}$, Plots of relative rectifications of AMPA responses in GluR1-GFP and GluR4-GFP-expressing neurons against expression levels of GluR1-GFP and GluR4-GFP in layer 4 tissues after different expression times.
}

neurons against the levels of GluR4-GFP and GluR1-GFP expression revealed a correlation of synaptic delivery of GluR4GFP but not GluR1-GFP with protein expression levels (Fig. 6E). These results suggest that protein expression as well as synaptic activity have different effects on synaptic trafficking of GluR1 and GluR4 in layer 4 cortical neurons.

\section{Synapse-specific trafficking in layer 5 pyramidal neurons}

Does synapse-specific trafficking of AMPA-Rs take place in other cortical neurons? To address this question, synaptic involvement of GluR1 and GluR4 in large tufted layer 5 pyramidal neurons was examined. Unlike layer 4 stellate neurons, large tufted layer 5 pyramidal neurons receive and integrate excitatory synaptic inputs via intracortical connections from many different types of neurons in cortical layers 2-6 (Markram et al., 1997; Reyes and Sakmann, 1999; Lefort et al., 2009). In addition, large tufted layer 5 pyramidal neurons also receive thalamocortical and intercortical inputs via layer 1 synapses (Herkenham, 1980; Cauller et al., 1998; Zhu and Zhu, 2004; De Paola et al., 2006), which are important for relaying attention-related signals and initiating dendritic action potentials (Cauller and Kulics, 1991; Jones, 2001; Larkum et al., 2001; Larkum and Zhu, 2002; Zhu and Zhu, 2004). To determine the contributions of distinct AMPA-Rs to these two populations of synapses in layer 5 neurons, I developed another new experimental approach that combined an in vitro intact cortical layer 1 input-layer 5 cell slice preparation (Zhu, 2000) with the in vivo recombinant protein delivery technique (McCormack et al., 2006) (Fig. 7A) (see also Materials and Methods). In this case, GFP-tagged recombinant proteins were virally delivered into layer 5 of the rat barrel cortex (McCormack et al., 2006). After $\sim 16 \mathrm{~h}$ for expression, cortical layer 1 input-layer 5 cell slices were prepared, and monosynaptic EPSCs of L1 and intracortical fiber origin were elicited in tufted layer 5 pyramidal neurons as described previously (Zhu, 2000; Larkum and Zhu, 2002). As with layer 4 stellate neurons, paired-pulse stimuli evoked facilitating responses in the intracortical pathway and depressing responses in the L1 pathway in expressing and nonexpressing layer 5 pyramidal neurons (data not shown). In addition, L1 responses had longer latency, slower time course, more rectified AMPA responses, and larger ratio of NMDA and AMPA responses compared with intracortical synaptic responses (Fig. 7). These results are expected because of the more distally located L1 stimulating electrode, more severe dendritic filtering and poorer voltage clamp (worse when clamped at $+40 \mathrm{mV}$ ), and larger contribution of NMDA-Rs to transmission at distal L1 synapses compared with the intracortical synaptic inputs (Schiller et al., 1997; Zhu, 2000).

To determine whether GluR1-containing AMPA-Rs mediate L1 and intracortical synaptic transmission, GluR1-GFP or GluR1ct-GFP was expressed in large tufted layer 5 pyramidal neurons (Fig. 7A). Compared with nearby nonexpressing neurons, GluR1-GFP-expressing layer 5 neurons had enhanced rectification of AMPA responses from intracortical synapses but not from L1 synapses (Fig. 7B), indicating selective insertion of GluR1-GFP at intracortical synapses. Accordingly, GluR1ctGFP-expressing layer 5 neurons had depressed AMPA responses from intracortical synapses $(\sim 25 \%)$ but not from L1 synapses (Fig. 7C). NMDA responses were not different between GluR1ctGFP-expressing and nonexpressing neurons (Fig. 7C). Together, these results indicate that GluR1-containing AMPA-Rs mediate intracortical transmission but do not mediate L1 transmission.

To determine whether GluR4-containing AMPA-Rs mediate intracortical and L1 transmission, GluR4-GFP or GluR4ct-GFP 

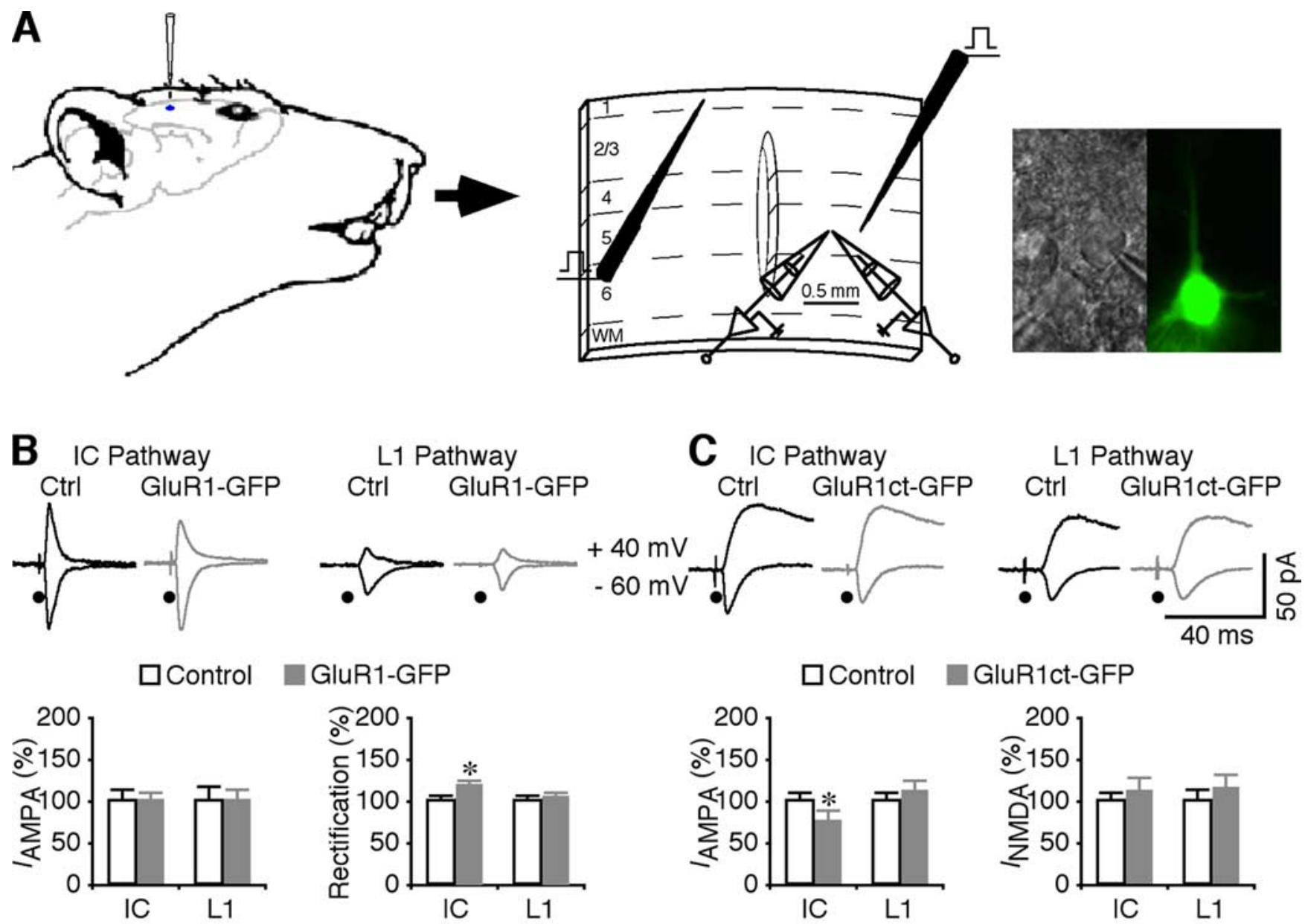

GluR1-GFP

口Control

GluR1ct-GFP
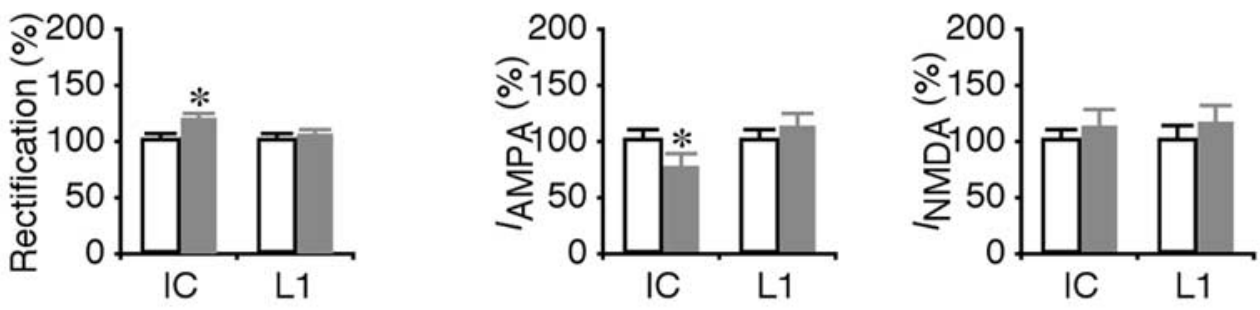

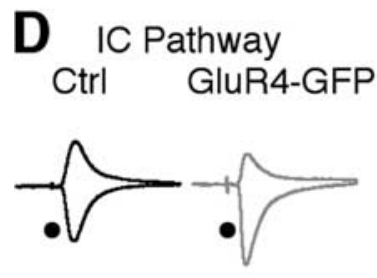

$\square$ Control

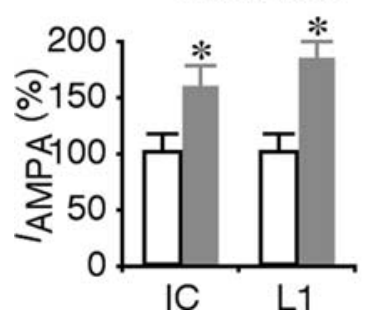

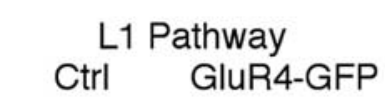

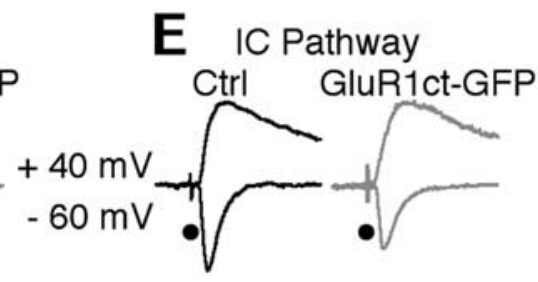

\section{L1 Pathway Ctrl GluR1ct-GFP}

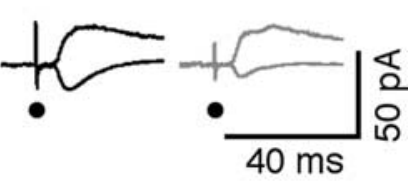

Figure 7. GluR1 and GluR4 differentially mediate transmission in layer 5 pyramidal neurons. $\boldsymbol{A}$, Left and middle, Schematic drawing of the in vivo injection of viral constructs, in vitro stimulating and recording electrode locations in the cortical L1 input-layer 5 cell slice preparation. WM, White matter. Right, Simultaneous recordings, made under transmitted light illumination (bottom), from pairs of recombinant protein-expressing neurons, identified by GFP fluorescence (top) and nearby nonexpressing control neurons in layer 5. B, Top, Evoked AMPA-R-mediated responses from intracortical (IC) and distal dendritic (L1) synapses recorded from nonexpressing (Ctrl) and GluR1-GFP-expressing (exp) neurons. Bottom left, AMPA responses in GluR1-GFP-expressing neurons from intracortical (Ctrl, $-51.9 \pm 7.7 \mathrm{pA}$; exp, $-52.4 \pm 5.3 \mathrm{pA} ; n=15 ; p=0.96)$ and L1 (Ctrl, $-36.7 \pm 7.0 \mathrm{pA} ; \exp ,-37.0 \pm 5.4 \mathrm{pA} ; n=15 ; p=0.73)$ synapses. Bottom right, Rectification of GluR1-GFP-expressing neurons from intracortical (Ctrl, $1.44 \pm 0.09 ; \exp , 1.71 \pm 0.07 ; n=15 ; p<0.005)$ and L1 (Ctrl, $1.88 \pm 0.14 ; \exp , 1.92 \pm 0.13 ; n=15 ; p=0.53)$ synapses. C, Top, Evoked AMPA-R- and NMDA-R-mediated responses from intracortical and distal dendritic synapses recorded from nonexpressing (Ctrl) and GluR1ct-GFP-expressing neurons. Bottom left, AMPA responses in GluR1ct-GFP-expressing neurons from intracortical (Ctrl, $-41.3 \pm 4.9 \mathrm{pA} ; \mathrm{exp},-31.1 \pm 5.1 \mathrm{pA} ; n=10 ; p<0.01)$ and L1 (Ctrl, $-26.4 \pm 2.7 \mathrm{pA} ; \mathrm{exp},-28.8 \pm 4.5 \mathrm{pA} ; n=10$; $p=0.39$ ) synapses. Bottom right, NMDA responses in GluR1ct-GFP-expressing neurons from intracortical (Ctrl, $50.0 \pm 5.2 \mathrm{pA} ; \exp , 57.9 \pm 10.4 \mathrm{pA} ; n=10 ; p=0.72)$ and L1 (Ctrl, $46.2 \pm 5.9 \mathrm{pA}$; $\exp , 52.0 \pm 9.1 \mathrm{pA} ; n=10 ; p=0.14$ ) synapses. D, Top, Evoked AMPA-R-mediated responses from intracortical and L1 synapses recorded from nonexpressing (Ctrl) and GluR4 - (Figure legend continues.) 
was expressed in large tufted layer 5 pyramidal neurons. Layer 5 neurons expressing GluR4-GFP had enhanced rectification and amplitude of AMPA responses from intracortical and L1 synapses (Fig. 7D), indicating synaptic insertion of GluR4-GFP at both intracortical and L1 synapses. In addition, layer 5 neurons expressing GluR4ct-GFP had depressed AMPA responses from both intracortical $(\sim 25 \%)$ and L1 $(\sim 50 \%)$ synapses; the amounts of depression between these two populations of synapses were significantly different (Fig. 7E). NMDA responses were not different between GluR4ct-GFP-expressing and nonexpressing neurons (Fig. $7 E$ ). These results indicate that GluR4-containing AMPA-Rs traffic into both intracortical and L1 synapses, and they mediate a larger proportion of L1 transmission than intracortical transmission.

Synaptic AMPA-R trafficking regulates transmission kinetics It is still unclear whether synapse-specific trafficking of AMPA-Rs containing different subunits, which display distinct gating properties (Mosbacher et al., 1994; Geiger et al., 1995; Jonas, 2000), is responsible for the difference in transmission kinetics at different types of synapses in cortical neurons. In addition, it remains unknown whether previous synaptic activity, which differentially controls synaptic delivery of distinct AMPA-Rs (Figs. 2-5), may further tune transmission kinetics at individual synapses. To address these questions, GluR1ct-GFP, GluR4ct-GFP, or GluR2ct-GFP was expressed to selectively block synaptic trafficking of GluR1-, GluR4-, or GluR2containing AMPA-Rs in layer 4 stellate neurons. Because expression of these constructs reduced amplitudes and rise times of AMPA responses of expressing neurons, only decay time constants of evoked EPSCs were compared (Fig. 8A-C). Expression of GluR1ct-GFP in layer 4 neurons reduced decay time constants of the evoked EPSCs from intracortical synapses (control, $5.90 \pm$ $0.37 \mathrm{~ms}$; expressing, $4.97 \pm 0.47 \mathrm{~ms} ; n=18 ; p<0.05$ ) but had no effect on those from thalamocortical synapses (control, $4.09 \pm$ $0.24 \mathrm{~ms}$; expressing, $4.11 \pm 0.32 \mathrm{~ms} ; n=18 ; p=0.78$ ), consistent with the selective involvement of GluR1 in intracortical transmission (Fig. 2). Moreover, expression of GluR4ct-GFP increased decay time constants of the evoked EPSCs from both intracortical and thalamocortical synapses (control, $5.83 \pm 0.51 \mathrm{~ms}$; expressing, $6.98 \pm 0.48 \mathrm{~ms} ; n=18 ; p<0.05$ for intracortical synapses; control, $3.98 \pm 0.25 \mathrm{~ms}$; expressing, $5.99 \pm 0.35 \mathrm{~ms} ; n=18 ; p<$ 0.0005 for thalamocortical synapses), consistent with the in-

$\leftarrow$

(Figure legend continued.) GFP-expressing neurons. Bottom left, AMPA responses in GluR4GFP-expressing neurons from intracortical (Ctrl, $-35.9 \pm 6.2 \mathrm{pA} ; \exp ,-56.5 \pm 7.0 \mathrm{pA} ; n=$ $11 ; p<0.005)$ and $\mathrm{L} 1(\mathrm{Ctrl},-24.6 \pm 4.5 \mathrm{pA} ; \exp ,-45.0 \pm 3.8 \mathrm{pA} ; n=11 ; p<0.005)$ synapses. Bottom right, Rectification of GluR4 -GFP-expressing neurons from intracortical (Ctrl, $1.43 \pm 0.12 ; \exp , 2.14 \pm 0.19 ; n=11 ; p<0.005)$ and L 1 (Ctrl, $1.62 \pm 0.15 ; \exp , 2.25 \pm 0.17$ $n=11 ; p<0.005)$ synapses. Note that the rectification in control neurons at intracortical synapses was significantly smaller than that at L1 synapses $(n=26 ; p<0.005)$. $\boldsymbol{E}$, Top, Evoked AMPA-R- and NMDA-R-mediated responses from intracortical and distal dendritic synapses recorded from nonexpressing (Ctrl) and GluR4ct-GFP-expressing neurons. Bottom left, AMPA responses in GluR4ct-GFP-expressing neurons from intracortical ( $\mathrm{Ctrl},-53.6 \pm 3.6 \mathrm{pA}$; exp, $-40.7 \pm 5.8 \mathrm{pA} ; n=12 ; p<0.005)$ and $\mathrm{L} 1(\mathrm{Ctrl},-33.0 \pm 4.7 \mathrm{pA} ; \exp ,-15.1 \pm 1.9 \mathrm{pA} ;$ $n=12 ; p<0.005)$ synapses. Bottom right, NMDA responses in GluR4ct-GFP-expressing neurons from intracortical (Ctrl, $53.2 \pm 4.8 \mathrm{pA} ; \exp , 49.4 \pm 5.8 \mathrm{pA} ; n=12 ; p=0.35)$ and L1 (Ctrl, $37.2 \pm 3.4 \mathrm{pA} ; \exp , 36.1 \pm 5.9 ; n=12 ; p=0.75)$ synapses. Note that the depression in expressing neurons $(n=12 ; p<0.005)$ at intracortical synapses was significantly smaller than that at L1 synapses and that the ratio of NMDA and AMPA responses in control neurons at intracortical synapses were significantly smaller than that at $\mathrm{L} 1$ synapses $(n=22 ; p<0.005)$. AMPA-R- and NMDA-R-mediated current amplitudes and SEs were normalized to average values from control cells. ${ }^{*} p<0.05$ (Wilcoxon's test).
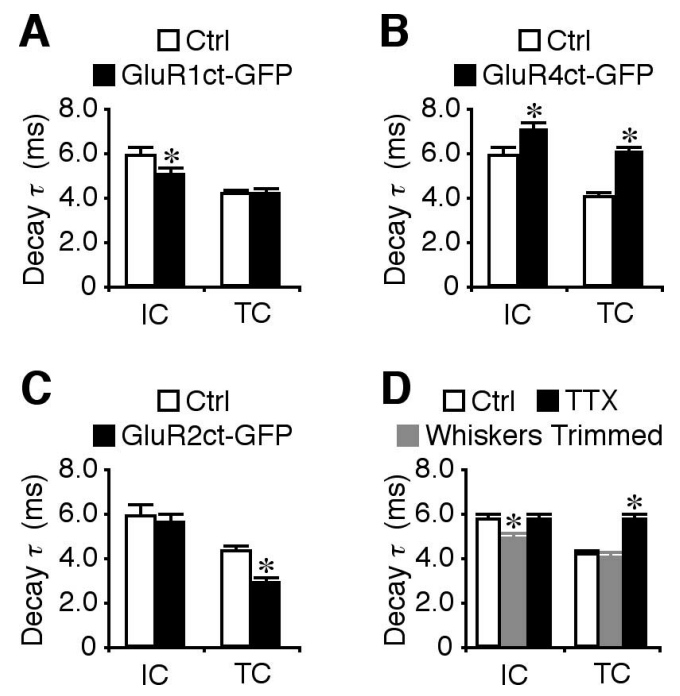

Figure 8. Synaptic AMPA-R trafficking modulates kinetics of cortical transmission. $A$, Decay time constant of the evoked EPSC in GluR1ct-GFP-expressing neurons from intracortical (IC: $\tau$; Ctrl, $5.90 \pm 0.37 \mathrm{~ms} ; \exp , 4.97 \pm 0.47 \mathrm{~ms} ; n=18 ; p<0.05)$ and thalamocortical (TC: $\tau$; Ctrl, $4.09 \pm 0.24 \mathrm{~ms} ; \exp , 4.11 \pm 0.32 \mathrm{~ms} ; n=18 ; p=0.78$ ) synapses. $\boldsymbol{B}$, Decay time constant of the evoked EPSCs in GluR4ct-GFP-expressing neurons from intracortical $(\tau ;$ Ctrl, $5.83 \pm 0.51$ $\mathrm{ms}$; $\exp , 6.98 \pm 0.48 \mathrm{~ms} ; n=18 ; p<0.05)$ and thalamocortical $(\tau ;$ Ctrl, $3.98 \pm 0.25 \mathrm{~ms}$; $\exp$, $5.99 \pm 0.35 \mathrm{~ms} ; n=18 ; p<0.0005)$ synapses. C, Decay time constant of the evoked EPSCs in GluR2ct-GFP-expressing neurons from intracortical ( $\tau$; Ctrl, $5.82 \pm 0.57 \mathrm{~ms}$; exp, $5.59 \pm 0.47$ $\mathrm{ms} ; n=14 ; p=0.88$ ) and thalamocortical ( $\tau$; Ctrl, $4.23 \pm 0.33 \mathrm{~ms} ; \exp , 2.89 \pm 0.26 \mathrm{~ms} ; n=$ $14 ; p<0.05$ ) synapses. ${ }^{*} p<0.05$ (Wilcoxon's test). $\boldsymbol{D}$, Decay time constant of the evoked EPSCs from intracortical ( $\tau$; Ctrl, $5.71 \pm 0.28 \mathrm{~ms}, n=40$; whiskers trimmed, $4.87 \pm 0.22 \mathrm{ms,}$ $n=41, p<0.05 ; \operatorname{TTX}, 5.76 \pm 0.31 \mathrm{~ms}, n=45, p=0.76)$ and thalamocortical $(\tau ; \mathrm{Ctrl}, 4.12 \pm$ $0.18 \mathrm{~ms}, n=40$; whiskers trimmed, $4.07 \pm 0.17 \mathrm{~ms}, n=41, p=0.97 ; \mathrm{TTX}, 5.68 \pm 0.26 \mathrm{~ms}$, $n=45, p<0.0005)$ synapses from rats with whiskers trimmed or cortical infusion of TTX. ${ }^{*} p<$ 0.05 (Mann-Whitney rank sum nonparametric test).

volvement of GluR4 in both intracortical and thalamocortical transmission (Fig. 4). Furthermore, expression of GluR2ct-GFP had no effect on decay time constants of the evoked EPSCs from intracortical synapses (control, $5.82 \pm 0.57 \mathrm{~ms}$; expressing, $5.59 \pm 0.47 \mathrm{~ms} ; n=14 ; p=0.88$ ) but decreased those from thalamocortical synapses (control, $4.23 \pm 0.33 \mathrm{~ms}$; expressing, $2.89 \pm 0.26 \mathrm{~ms} ; n=14 ; p<0.05$ ), consistent with the results that GluR2-containing AMPA-Rs contribute to $\sim 50 \%$ intracortical and thalamocortical transmission, whereas GluR1- and GluR4containing AMPA-Rs contribute approximately equally to the rest of intracortical transmission and GluR4-containing AMPA-Rs contribute to all the rest of thalamocortical transmission (Figs. 2, 4, 5). These results indicate that selectively blocking synaptic trafficking of GluR1-, GluR4-, or GluR2-containing AMPA-Rs differentially alters transmission kinetics at different types of synapses in layer 4 neurons.

To examine the effects of previous activity history on transmission kinetics in layer 4 stellate neurons, whisker trimming or cortical TTX infusion was used to manipulate different forms of activity (Fig. $8 D$ ). Whisker trimming decreased decay time constants of the evoked EPSCs from intracortical synapses $(4.87 \pm$ $0.22 \mathrm{~ms} ; n=41 ; p<0.05)$ but had no effect on those from thalamocortical synapses ( $4.07 \pm 0.17 \mathrm{~ms} ; n=41 ; p=0.97)$, consistent with the blockade of synaptic insertion of GluR1containing AMPA-Rs at intracortical synapses (Figs. 2, 8A-C). However, cortical infusion of TTX had no net effect on decay time constants of the evoked EPSCs from intracortical synapses $(5.76 \pm 0.31 \mathrm{~ms} ; n=45 ; p=0.76)$ but increased those from thalamocortical synapses $(5.68 \pm 0.26 \mathrm{~ms} ; n=45 ; p<0.0005)$, 
consistent with the blockade of synaptic insertion of both GluR1and GluR4-containing AMPA-Rs at intracortical synapses and blockade of synaptic insertion of only GluR4-containing AMPA-Rs at thalamocortical synapses (Figs. 2, 4, 8A-C) (McCormack et al., 2006). Together, these results indicate that whisker-dependent activity decelerates transmission kinetics, whereas whisker-independent activity accelerates transmission kinetics at synapses in layer 4 neurons.

\section{Synaptic AMPA-R trafficking regulates synaptic integration}

Changes in transmission kinetics affect synaptic integration (Cathala et al., 2003; Wehr and Zador, 2003; Daw et al., 2006). To determine how synaptic trafficking of distinct GluR1-, GluR2-, and GluR4-containing AMPA-Rs differentially affects synaptic integration, GluR4ct-red fluorescent protein (RFP) and GluR1ct-GFP or GluR4ct-RFP and GluR2ct-GFP were expressed simultaneously in layer 4 stellate neurons (Fig. 9A). GluR4ct-RFP-expressing neurons had slower quantal EPSCs compared with nearby GluR1ct-GFP-expressing neurons in the intracortical pathway $(0.88 \pm 0.04$ vs $0.62 \pm 0.04 \mathrm{~ms}, n=11, p<$ 0.005 for rise time; $3.62 \pm 0.23$ vs $2.60 \pm 0.15 \mathrm{~ms}, n=11, p<$ 0.005 for $\tau$ ) and nearby GluR2ct-GFP-expressing neurons in the thalamocortical pathway $(0.89 \pm 0.04$ vs $0.57 \pm 0.02 \mathrm{~ms}, n=10$, $p<0.01$ for rise time; $3.68 \pm 0.25$ vs $1.98 \pm 0.12 \mathrm{~ms}, n=10, p<$ 0.01 for $\tau$ ) (Fig. $9 B$ ), consistent with the idea that blocking synaptic delivery of endogenous GluR1-, GluR2-, and GluR4containing AMPA-Rs had different effects on intracortical and thalamocortical transmission kinetics. Moreover, in currentclamp mode, GluR4ct-RFP-, GluR1ct-GFP-, and GluR2ct-GFPexpressing neurons had the same basic membrane properties (supplemental Fig. S1 B, C, available at www.jneurosci.org as supplemental material) but differed in integration of synaptic inputs. GluR4ct-RFP-expressing neurons had slower EPSPs and an increased proportion of second EPSPs evoking action potentials compared with GluR1ct-GFP-expressing neurons in the intracortical pathway, and increased action potential jittering and longer latency from EPSP onset to action potential initiation compared with GluR2ct-GFP-expressing neurons in the thalamocortical pathway (Fig. 9C,D). Together, these results indicate that increasing synaptic GluR4 speeds up transmission kinetics and increases action potential timing precision, whereas increasing synaptic GluR1 slows down transmission kinetics and boosts synaptic summation.

\section{Discussion}

In this study, I have demonstrated that GluR1-containing AMPA-Rs selectively traffic into and mediate transmission at intracortical synapses, GluR4-containing AMPA-Rs more extensively traffic into and mediate transmission at thalamocortical synapses, and GluR2-containing AMPA-Rs evenly traffic into and mediate transmission at intracortical and thalamocortical synapses. These three trafficking events require sensory experience-dependent synaptic activity, experience-independent synaptic activity, or no synaptic activity, respectively. Synapsespecific AMPA-R trafficking coarsely sets transmission kinetics at different populations of synapses, whereas experience-dependent and -independent synaptic activity finely tune transmission kinetics at individual synapses in single cortical neurons. Alterations of transmission kinetics resulted from synaptic delivery of different AMPA-Rs mold synaptic integrative properties, including action potential time precision and ability of summation.

\section{Synapse-specific AMPA-R trafficking}

Previous studies have reported synapse-specific expression or function of GluR4-containing and GluR2-lacking AMPA-Rs in central neurons (Geiger et al., 1997; Rubio and Wenthold, 1997; Tóth and McBain, 1998; Gardner et al., 2001). This study shows that GluR1-containing AMPA-Rs selectively traffic into and mediate transmission at intracortical synapses but not thalamocortical or L1 synapses of single layer 4 stellate neurons and single large tufted layer 5 pyramidal neurons in the barrel cortex. In addition, functional incorporation of GluR1-containing AMPA-Rs is also synapse specific in layer $2 / 3$ neurons of the barrel cortex (our unpublished results) and thalamocortical neurons in the thalamus (Kielland et al., 2009). These findings suggest synapse-specific incorporation of GluR1 to be a general phenomenon in central neurons. Recently, an elegant study has demonstrated that layer 4 stellate neurons receive excitatory inputs primarily from other layer 4 neurons but only a very few or no input from neurons in other cortical layers (Lefort et al., 2009) (see also Schubert et al., 2003; Lee and Sherman, 2008). Moreover, the majority (but not all) of the intracortical synapses on layer 4 neurons are from other layer 4 neurons in the same barrel (Feldmeyer et al., 1999; Brecht and Sakmann, 2002; Schubert et al., 2003). Consistent with this idea, the intracortical stimulation threshold increases sharply, and evoked responses are dramatically reduced once the stimulating electrode moves out of the barrel in which recorded neurons are located (our unpublished observation). Together, the results suggest that GluR1 mediates transmission of local intracortical connections formed between layer 4 stellate neurons within the same barrel. However, large tufted layer 5 pyramidal neurons receive synaptic inputs from many different types of neurons in layers 2-6 (Markram et al., 1997; Reyes and Sakmann, 1999; Lefort et al., 2009). Thus, it remains to be determined whether GluR1 mediates transmission of all or only some types of intracortical synapses formed on layer 5 neurons.

\section{Functional significance of synapse-specific AMPA-R trafficking}

Persistent changes of synaptic dynamics may underlie sensory experience-dependent cortical plasticity (Diamond et al., 1993; Buonomano and Merzenich, 1998; Fox, 2002). A previous report has shown that sensory experience modifies presynaptic release properties (Finnerty et al., 1999), but whether sensory experience affects postsynaptic transmission kinetics is still unknown. The results from this study show, for the first time, that levels of activities (e.g., sensory experience-dependent and -independent synaptic activities) control synaptic delivery of GluR1-, GluR2-, and GluR4-containing AMPA-Rs and finely tune postsynaptic transmission kinetics at individual synapses in layer 4 stellate neurons. Thus, the previous history of synaptic activity regulates both efficacy and kinetics of postsynaptic transmission, suggesting a novel and significant role for postsynaptic modification of transmission in cortical plasticity. These results also lend support to the notion that cortical synapses exhibit varied transmission efficacy and kinetics and thus reflect a high capacity for plasticity (Stern et al., 1992; Markram et al., 1997; Gil et al., 1999; Petersen et al., 2003; Kalisman et al., 2005; Cheetham et al., 2007).

Whether synapse-specific trafficking and incorporation of AMPA-Rs with distinct gating properties may affect information processing remains unclear. Here, I show that synaptic delivery of fast GluR4-containing AMPA-Rs into thalamocortical synapses increases action potential timing precision (Fig. 9), perfect for thalamocortical (and L1) synapses to serve as coincidence detec- 
A

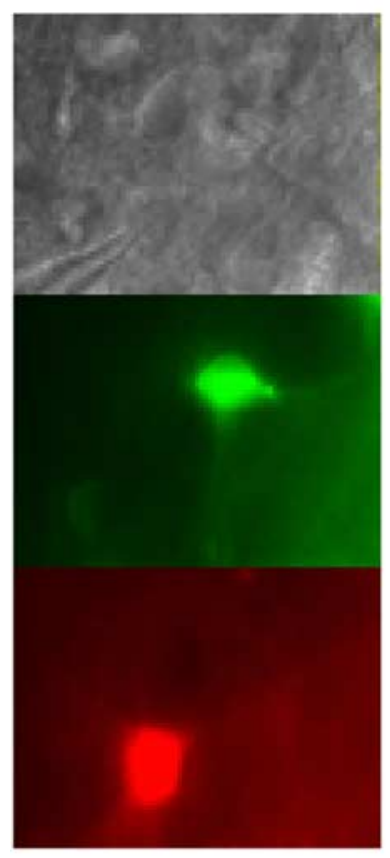

C

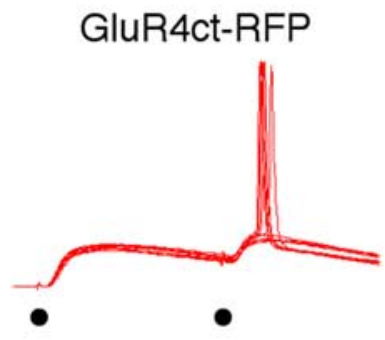

GluR4ct-RFP

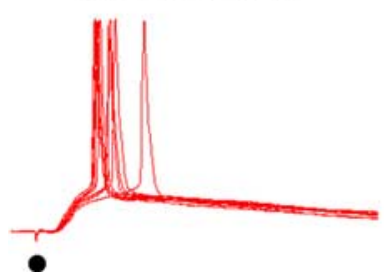

B

B IC Pathway

GluR4ct-RFP GluR1ct-GFP
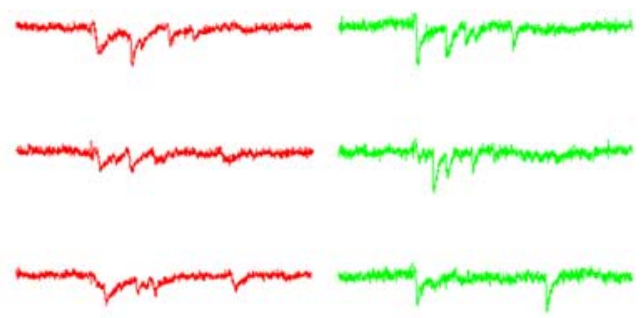

TC Pathway

GluR4ct-RFP GluR2ct-GFP
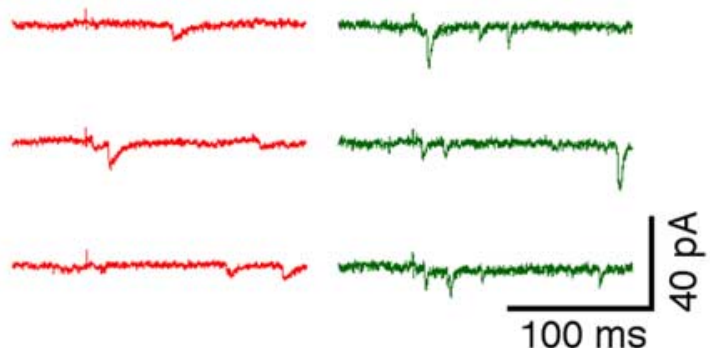
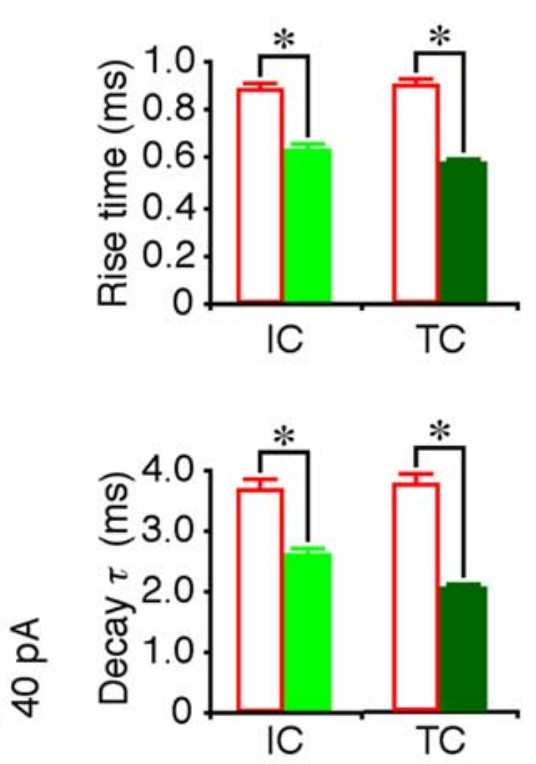

\section{GluR4ct-RFP \\ GluR1ct-GFP \\ GluR2ct-GFP}

IC Pathway

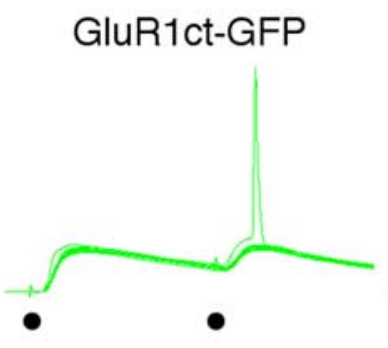

TC Pathway

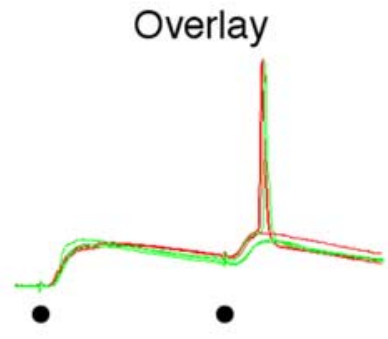

Overlay

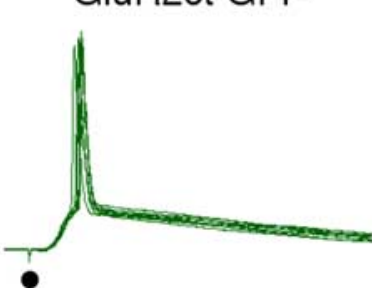

D

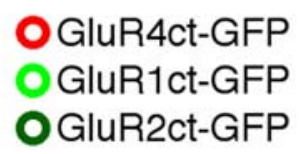

Figure 9. Synaptic AMPA-R trafficking regulates synaptic integration. $\boldsymbol{A}$, Simultaneous recordings, made under transmitted light illumination (top), from pairs of nearby recombinant protein expressing layer 4 neurons, identified by GFP (middle) and RFP (bottom) fluorescence. B, Left, Asynchronous quantal EPSCs from intracortical (IC) synapses of GluR4ct-RFP- and GluR1ct-GFPexpressing neurons and from thalamocortical (TC) synapses of GluR4ct-RFP- and GluR2ct-GFP-expressing neurons. Top right, Rise time of asynchronous quantal EPSCs from intracortical synapses of GluR4ct-RFP- and GluR1ct-GFP-expressing neurons (GluR4ct-RFP, $0.88 \pm 0.04 \mathrm{~ms}$; GluR1ct-GFP, $0.62 \pm 0.04 \mathrm{~ms} ; n=11 ; p<0.005$ ) and from thalamocortical synapses of GluR4ct-RFP- and GluR2ct-GFP-expressing neurons (GluR4ct-RFP, $0.89 \pm 0.04 \mathrm{~ms}$; GluR2ct-GFP, $0.57 \pm 0.02 \mathrm{~ms} ; n=10 ; p<0.01$ ). Bottom right, Decay time constant of asynchronous quantal EPSCs from intracortical synapses of GluR4ct-RFP- and GluR1ct-GFP-expressing neurons ( $\tau$; GluR4ct-RFP, $3.62 \pm 0.23 \mathrm{~ms} ;$ GluR1ct-GFP, $2.60 \pm 0.15 \mathrm{~ms} ; n=11 ; p<0.005)$ and from thalamocortical synapses of GluR4ct-RFP- and GluR2ct-GFP-expressing neurons ( $\tau$; GluR4ct-RFP, $3.68 \pm 0.25 \mathrm{~ms}$; GluR2ct-GFP, $1.98 \pm 0.12 \mathrm{~ms} ; n=10 ; p<0.01$ ). C, Top, Ten consecutive superimposed intracortical EPSPs in a pair of nearby GluR4ct-RFP-and GluR1ct-GFP-expressing neurons. Bottom, Ten consecutive superimposed thalamocortical EPSPs in a pair of nearby GluR4ct-RFP and GluR2ct-GFP-expressing neurons. Overlay includes three representative evoked responses from each cell pair. D, Top, Percentage of second EPSPs that trigger action potential in GluR4ct-RFP- and GluR1ct-GFP-expressing neurons (GluR4ct-RFP, $46.0 \pm 6.6 \%$; GluR1ct-GFP, $3.2 \pm 1.3 \% ; n=10 ; p<0.01$ ). Bottom, Range of action potential jitter (GluR4ct-RFP, $10.1 \pm 3.8$ ms; GluR2ct-GFP, $2.1 \pm 0.5 \mathrm{~ms} ; n=8 ; p<0.05$ ) and EPSP-action potential time delay (GluR4ct-RFP, $7.5 \pm 0.4 \mathrm{~ms} ; \mathrm{GluR2ct-GFP}, 6.2 \pm 0.5 \mathrm{~ms} ; n=8 ; p<0.05$ ) in GluR4ct-RFP-and GluR2ct-GFP-expressing neurons. ${ }^{*} p<0.05$ (Wilcoxon's test). 
tors and/or relays of synchronous sensory inputs, whereas synaptic delivery of slow GluR1-containing AMPA-Rs boosts synaptic summation (Fig. 9), ideal for intracortical synapses to operate as integrators to calculate and/or amplify recurrent cortical inputs (Larkum et al., 1999; Jonas, 2000; Gardner et al., 2001; Bruno and Sakmann, 2006; Rigas and Castro-Alamancos, 2007). Notably, the results indicate that experience-dependent activity selectively drives GluR1-containing AMPA-Rs into intracortical synapses and prolongs transmission time course, whereas experienceindependent spontaneous activity preferentially drives more GluR4-containing AMPA-Rs into thalamocortical synapses and shortens transmission time course. Activity-independent synaptic exchange, which replaces GluR1- and GluR4-containing AMPA-Rs with GluR2/3 AMPA-Rs (Zhu et al., 2000; Takahashi et al., 2003; McCormack et al., 2006), may reset transmission kinetics. Thus, transmission kinetics at individual synapses may vary to some extent depending on the previous synaptic activity history, but the overall transmission kinetics and integration properties at different types of synapses are determined by synapse-specific trafficking of distinct AMPA-Rs.

Synaptic delivery of AMPA-Rs with long cytoplasmic termini, including GluR1, GluR2L, and GluR4, enhances synaptic transmission (Kessels and Malinow, 2009). Interestingly, GluR4 (e.g., in the cortex and thalamus) or GluR2L (e.g., in the hippocampus) and GluR1 are coexpressed at the same time in many different types of adult neurons (Kolleker et al., 2003; Qin et al., 2005; McCormack et al., 2006; Hu et al., 2008; Kielland et al., 2009). Importantly, GluR4- (or GluR2L-) and GluR1-containing AMPA-Rs differ significantly in their properties and involvement in physiological functions. For example, the rules governing synaptic trafficking of these AMPA-Rs are different. Whereas spontaneous or experience-independent synaptic activity is sufficient for driving GluR4- and GluR2L-containing AMPA-Rs into synapses, strong or experience-dependent synaptic activity is required for synaptic incorporation of GluR1-containing AMPA-Rs (Zhu et al., 2000; Kolleker et al., 2003; Takahashi et al., 2003; Qin et al., 2005; McCormack et al., 2006; Hu et al., 2008; Kielland et al., 2009). The results from this study further suggest that experience-dependent activity, instead of the expression level of GluR1, limits the amount of synaptic incorporation of GluR1, which is in concert with the findings that only a small percentage of GluR1 receptors are located at synapses and the maximal LTP-inducing stimuli drive approximately the same amount of GluR1 receptors into synapses, whereas the majority of GluR1 receptors are present at nonsynaptic sites (Shi et al., 1999; Zamanillo et al., 1999; Kielland et al., 2009). However, action potential-dependent spontaneous synaptic activity, which is prevalent in the cortex and hippocampus in all behavioral states (Zhu and Connors, 1999; Buzsáki et al., 2002; Margrie et al., 2002), seem not ideal for regulating the amount of synaptic incorporation of GluR2L- and GluR4-containing AMPA-Rs. Thus, it is plausible that the expression of GluR4, which is regulated at low levels in the cortex (Fig. 6C) (see also Petralia and Wenthold, 1992), rather than spontaneous activity, controls the amount of synaptic insertion of GluR4 in cortical neurons. Moreover, synapse-specific incorporations of GluR1 and GluR4 differentially influence how information is integrated. Finally, it is possible that GluR2L- (or GluR4-) and GluR1-containing AMPA-Rs receptors may mediate different forms of plasticity and distinct forms of learning behaviors (Zamanillo et al., 1999; Qin et al., 2005; Rumpel et al., 2005; Schmitt et al., 2005; Hu et al., 2008; Kessels and Malinow, 2009). Thus, coexpression of multiple AMPA-Rs with long cytoplasmic termini may allow neurons to participate in different forms of synaptic potentiation and integration processes.

\section{References}

Abdul-Ghani MA, Valiante TA, Pennefather PS (1996) $\mathrm{Sr}^{2+}$ and quantal events at excitatory synapses between mouse hippocampal neurons in culture. J Physiol 495:113-125.

Agmon A, Connors BW (1991) Thalamocortical responses of mouse somatosensory (barrel) cortex in vitro. Neuroscience 41:365-379.

Brecht M, Sakmann B (2002) Dynamic representation of whisker deflection by synaptic potentials in spiny stellate and pyramidal cells in the barrels and septa of layer 4 rat somatosensory cortex. J Physiol 543:49-70.

Bruno RM, Sakmann B (2006) Cortex is driven by weak but synchronously active thalamocortical synapses. Science 312:1622-1627.

Buonomano DV, Merzenich MM (1998) Cortical plasticity: from synapses to maps. Annu Rev Neurosci 21:149-186.

Buzsáki G, Csicsvari J, Dragoi G, Harris K, Henze D, Hirase H (2002) Homeostatic maintenance of neuronal excitability by burst discharges in vivo. Cereb Cortex 12:893-899.

Castro-Alamancos MA (2002) Role of thalamocortical sensory suppression during arousal: focusing sensory inputs in neocortex. J Neurosci 22:9651-9655.

Cathala L, Brickley S, Cull-Candy S, Farrant M (2003) Maturation of EPSCs and intrinsic membrane properties enhances precision at a cerebellar synapse. J Neurosci 23:6074-6085.

Cauller LJ, Kulics AT (1991) The neural basis of the behaviorally relevant $\mathrm{N} 1$ component of the somatosensory-evoked potential in SI cortex of awake monkeys: evidence that backward cortical projections signal conscious touch sensation. Exp Brain Res 84:607-619.

Cauller LJ, Clancy B, Connors BW (1998) Backward cortical projections to primary somatosensory cortex in rats extend long horizontal axons in layer I. J Comp Neurol 390:297-310.

Cheetham CE, Hammond MS, Edwards CE, Finnerty GT (2007) Sensory experience alters cortical connectivity and synaptic function site specifically. J Neurosci 27:3456-3465.

Crair MC, Malenka RC (1995) A critical period for long-term potentiation at thalamocortical synapses. Nature 375:325-328.

Cruikshank SJ, Lewis TJ, Connors BW (2007) Synaptic basis for intense thalamocortical activation of feedforward inhibitory cells in neocortex. Nat Neurosci 10:462-468.

Daw MI, Bannister NV, Isaac JT (2006) Rapid, activity-dependent plasticity in timing precision in neonatal barrel cortex. J Neurosci 26:4178-4187.

De Paola V, Holtmaat A, Knott G, Song S, Wilbrecht L, Caroni P, Svoboda K (2006) Cell type-specific structural plasticity of axonal branches and boutons in the adult neocortex. Neuron 49:861-875.

Diamond ME, Armstrong-James M, Ebner FF (1993) Experiencedependent plasticity in adult rat barrel cortex. Proc Natl Acad Sci U S A 90:2082-2086.

Dodge FA Jr, Miledi R, Rahamimoff R (1969) Strontium and quantal release of transmitter at the neuromuscular junction. J Physiol 200:267-283.

Feldmeyer D, Egger V, Lubke J, Sakmann B (1999) Reliable synaptic connections between pairs of excitatory layer 4 neurones within a single "barrel” of developing rat somatosensory cortex. J Physiol 521:169-190.

Finnerty GT, Roberts LS, Connors BW (1999) Sensory experience modifies the short-term dynamics of neocortical synapses. Nature 400:367-371.

Fox K (2002) Anatomical pathways and molecular mechanisms for plasticity in the barrel cortex. Neuroscience 111:799-814.

Gardner SM, Trussell LO, Oertel D (2001) Correlation of AMPA receptor subunit composition with synaptic input in the mammalian cochlear nuclei. J Neurosci 21:7428-7437.

Geiger JR, Melcher T, Koh DS, Sakmann B, Seeburg PH, Jonas P, Monyer H (1995) Relative abundance of subunit mRNAs determines gating and $\mathrm{Ca}^{2+}$ permeability of AMPA receptors in principal neurons and interneurons in rat CNS. Neuron 15:193-204.

Geiger JR, Lübke J, Roth A, Frotscher M, Jonas P (1997) Submillisecond AMPA receptor-mediated signaling at a principal neuron-interneuron synapse. Neuron 18:1009-1023.

Gil Z, Connors BW, Amitai Y (1999) Efficacy of thalamocortical and intracortical synaptic connections: quanta, innervation, and reliability. Neuron 23:385-397.

Gu Y, Stornetta RL (2007) Synaptic plasticity, AMPA-R trafficking, and Ras-MAPK signaling. Acta Pharmacologica Sinica 28:928-936. 
Hardingham N, Fox K (2006) The role of nitric oxide and GluR1 in presynaptic and postsynaptic components of neocortical potentiation. J Neurosci 26:7395-7404.

Hayashi Y, Shi SH, Esteban JA, Piccini A, Poncer JC, Malinow R (2000) Driving AMPA receptors into synapses by LTP and CaMKII: requirement for GluR1 and PDZ domain interaction. Science 287:2262-2267.

Herkenham M (1980) Laminar organization of thalamic projections to the rat neocortex. Science 207:532-535.

Hu H, Qin Y, Bochorishvili G, Zhu Y, van Aelst L, Zhu JJ (2008) Ras signaling mechanisms underlying impaired GluR1-dependent plasticity associated with fragile X syndrome. J Neurosci 28:7847-7862.

Isaac JT, Crair MC, Nicoll RA, Malenka RC (1997) Silent synapses during development of thalamocortical inputs. Neuron 18:269-280.

Isaac JT, Ashby M, McBain CJ (2007) The role of the GluR2 subunit in AMPA receptor function and synaptic plasticity. Neuron 54:859-871.

Jonas P (2000) The time course of signaling at central glutamatergic synapses. News Physiol Sci 15:83-89.

Jones EG (2001) The thalamic matrix and thalamocortical synchrony. Trends Neurosci 24:595-601.

Kalisman N, Silberberg G, Markram H (2005) The neocortical microcircuit as a tabula rasa. Proc Natl Acad Sci U S A 102:880-885.

Kauer JA, Malenka RC (2007) Synaptic plasticity and addiction. Nat Rev Neurosci 8:844-858.

Kerchner GA, Nicoll RA (2008) Silent synapses and the emergence of a postsynaptic mechanism for LTP. Nat Rev Neurosci 9:813-825.

Kessels HW, Malinow R (2009) Synaptic AMPA receptor plasticity and behavior. Neuron 61:340-350.

Kielland A, Bochorishvili G, Corson J, Zhang L, Rosin DL, Heggelund P, Zhu JJ (2009) Activity patterns govern synapse-specific AMPA-R trafficking between deliverable and synaptic pools. Neuron 62:84-101.

Kolleker A, Zhu JJ, Schupp BJ, Qin Y, Mack V, Borchardt T, Köhr G, Malinow R, Seeburg PH, Osten P (2003) Glutamatergic plasticity by synaptic delivery of GluR-B(long)-containing AMPA receptors. Neuron 40:1199-1212.

Larkum ME, Zhu JJ (2002) Signaling of layer 1 and whisker-evoked $\mathrm{Ca}^{2+}$ and $\mathrm{Na}^{+}$action potentials in distal and terminal dendrites of rat neocortical pyramidal neurons in vitro and in vivo. J Neurosci 22:6991-7005.

Larkum ME, Zhu JJ, Sakmann B (1999) A new cellular mechanism for coupling inputs arriving at different cortical layers. Nature 398:338-341.

Larkum ME, Zhu JJ, Sakmann B (2001) Dendritic mechanisms underlying the coupling of the dendritic with the axonal action potential initiation zone of adult rat layer 5 pyramidal neurons. J Physiol 533:447-466.

Lee CC, Sherman SM (2008) Synaptic properties of thalamic and intracortical inputs to layer 4 of the first- and higher-order cortical areas in the auditory and somatosensory systems. J Neurophysiol 100:317-326.

Lefort S, Tomm C, Floyd Sarria JC, Petersen CC (2009) The excitatory neuronal network of the $\mathrm{C} 2$ barrel column in mouse primary somatosensory cortex. Neuron 61:301-316.

Margrie TW, Brecht M, Sakmann B (2002) In vivo, low-resistance, wholecell recordings from neurons in the anaesthetized and awake mammalian brain. Pflugers Arch 444:491-498.

Markram H, Lübke J, Frotscher M, Roth A, Sakmann B (1997) Physiology and anatomy of synaptic connections between thick tufted pyramidal neurones in the developing rat neocortex. J Physiol 500:409-440.

Martin LJ, Blackstone CD, Levey AI, Huganir RL, Price DL (1993) AMPA glutamate receptor subunits are differentially distributed in rat brain. Neuroscience 53:327-358.

McCormack SG, Stornetta RL, Zhu JJ (2006) Synaptic AMPA receptor exchange maintains bidirectional plasticity. Neuron 50:75-88.

Mosbacher J, Schoepfer R, Monyer H, Burnashev N, Seeburg PH, Ruppersberg JP (1994) A molecular determinant for submillisecond desensitization in glutamate receptors. Science 266:1059-1062.

Oliet SH, Malenka RC, Nicoll RA (1996) Bidirectional control of quantal size by synaptic activity in the hippocampus. Science 271:1294-1297.

Petersen CC, Grinvald A, Sakmann B (2003) Spatiotemporal dynamics of sensory responses in layer $2 / 3$ of rat barrel cortex measured in vivo by voltage-sensitive dye imaging combined with whole-cell voltage recordings and neuron reconstructions. J Neurosci 23:1298-1309.

Petralia RS, Wenthold RJ (1992) Light and electron immunocytochemical localization of AMPA-selective glutamate receptors in the rat brain. J Comp Neurol 318:329-354.
Qin Y, Zhu Y, Baumgart JP, Stornetta RL, Seidenman K, Mack V, van Aelst L, Zhu JJ (2005) State-dependent Ras signaling and AMPA receptor trafficking. Genes Dev 19:2000-2015.

Reyes A, Sakmann B (1999) Developmental switch in the short-term modification of unitary EPSPs evoked in layer 2/3 and layer 5 pyramidal neurons of rat neocortex. J Neurosci 19:3827-3835.

Rigas P, Castro-Alamancos MA (2007) Thalamocortical Up states: differential effects of intrinsic and extrinsic cortical inputs on persistent activity. J Neurosci 27:4261-4272.

Rubio ME, Wenthold RJ (1997) Glutamate receptors are selectively targeted to postsynaptic sites in neurons. Neuron 18:939-950.

Rumpel S, LeDoux J, Zador A, Malinow R (2005) Postsynaptic receptor trafficking underlying a form of associative learning. Science 308:83-88.

Schiller J, Schiller Y, Stuart G, Sakmann B (1997) Calcium action potentials restricted to distal apical dendrites of rat neocortical pyramidal neurons. J Physiol 505:605-616.

Schmitt WB, Sprengel R, Mack V, Draft RW, Seeburg PH, Deacon RM, Rawlins JN, Bannerman DM (2005) Restoration of spatial working memory by genetic rescue of GluR-A-deficient mice. Nat Neurosci 8:270-272.

Schubert D, Kötter R, Zilles K, Luhmann HJ, Staiger JF (2003) Cell typespecific circuits of cortical layer IV spiny neurons. J Neurosci 23:2961-2970.

Shepherd JD, Huganir RL (2007) The cell biology of synaptic plasticity: AMPA receptor trafficking. Annu Rev Cell Dev Biol 23:613-643.

Shi S, Hayashi Y, Esteban JA, Malinow R (2001) Subunit-specific rules governing AMPA receptor trafficking to synapses in hippocampal pyramidal neurons. Cell 105:331-343.

Shi SH, Hayashi Y, Petralia RS, Zaman SH, Wenthold RJ, Svoboda K, Malinow R (1999) Rapid spine delivery and redistribution of AMPA receptors after synaptic NMDA receptor activation. Science 284:1811-1816.

Stern P, Edwards FA, Sakmann B (1992) Fast and slow components of unitary EPSCs on stellate cells elicited by focal stimulation in slices of rat visual cortex. J Physiol 449:247-278.

Takahashi T, Svoboda K, Malinow R (2003) Experience strengthening transmission by driving AMPA receptors into synapses. Science 299:1585-1588

Tóth K, McBain CJ (1998) Afferent-specific innervation of two distinct AMPA receptor subtypes on single hippocampal interneurons. Nat Neurosci 1:572-578.

Wehr M, Zador AM (2003) Balanced inhibition underlies tuning and sharpens spike timing in auditory cortex. Nature 426:442-446.

White EL, Keller A (1989) Cortical circuits: synaptic organization of the cerebral cortex: structure, function, and theory. Boston: Birkhèauser.

White EL, Rock MP (1980) Three-dimensional aspects and synaptic relationships of a Golgi-impregnated spiny stellate cell reconstructed from serial thin sections. J Neurocytol 9:615-636.

Wright N, Glazewski S, Hardingham N, Phillips K, Pervolaraki E, Fox K (2008) Laminar analysis of the role of GluR1 in experience-dependent and synaptic depression in barrel cortex. Nat Neurosci 11:1140-1142.

Zamanillo D, Sprengel R, Hvalby O, Jensen V, Burnashev N, Rozov A, Kaiser KM, Köster HJ, Borchardt T, Worley P, Lübke J, Frotscher M, Kelly PH, Sommer B, Andersen P, Seeburg PH, Sakmann B (1999) Importance of AMPA receptors for hippocampal synaptic plasticity but not for spatial learning. Science 284:1805-1811.

Zhu JJ (2000) Maturation of layer 5 neocortical pyramidal neurons: amplifying salient layer 1 and layer 4 inputs by $\mathrm{Ca}^{2+}$ action potentials in adult rat tuft dendrites. J Physiol 526:571-587.

Zhu JJ, Connors BW (1999) Intrinsic firing patterns and whisker-evoked synaptic responses of neurons in the rat barrel cortex. J Neurophysiol 81:1171-1183.

Zhu JJ, Malinow R (2002) Acute versus chronic NMDA receptor blockade and synaptic AMPA receptor delivery. Nat Neurosci 5:513-514.

Zhu JJ, Esteban JA, Hayashi Y, Malinow R (2000) Postnatal synaptic potentiation: delivery of GluR4-containing AMPA receptors by spontaneous activity. Nat Neurosci 3:1098-1106.

Zhu JJ, Qin Y, Zhao M, Van Aelst L, Malinow R (2002) Ras and Rap control AMPA receptor trafficking during synaptic plasticity. Cell 110:443-455.

Zhu Y, Zhu JJ (2004) Rapid arrival and integration of ascending sensory information in layer 1 nonpyramidal neurons and tuft dendrites of layer 5 pyramidal neurons of the neocortex. J Neurosci 24:1272-1279. 